Louisiana State University

LSU Digital Commons

1979

\title{
Extrapituitary Regulation of the Circadian Rhythm of Plasma Corticosteroid Concentration in Rats.
}

John Edward Ottenweller

Louisiana State University and Agricultural \& Mechanical College

Follow this and additional works at: https://digitalcommons.Isu.edu/gradschool_disstheses

\section{Recommended Citation}

Ottenweller, John Edward, "Extrapituitary Regulation of the Circadian Rhythm of Plasma Corticosteroid Concentration in Rats." (1979). LSU Historical Dissertations and Theses. 3346.

https://digitalcommons.Isu.edu/gradschool_disstheses/3346

This Dissertation is brought to you for free and open access by the Graduate School at LSU Digital Commons. It has been accepted for inclusion in LSU Historical Dissertations and Theses by an authorized administrator of LSU Digital Commons. For more information, please contact gradetd@lsu.edu. 


\section{INFORMATION TO USERS}

This was produced from a copy of a document sent to us for microfilming. While the most advanced technological means to photograph and reproduce this document have been used, the quality is heavily dependent upon the quality of the material submitted.

The following explanation of techniques is provided to help you understand markings or notations which may appear on this reproduction.

1. The sign or "target" for pages apparently lacking from the document photographed is "Missing Page(s)". If it was possible to obtain the missing page(s) or section, they are spliced into the film along with adjacent pages. This may have necessitated cutting through an image and duplicating adjacent pages to assure you of complete continuity.

2. When an image on the film is obliterated with a round black mark it is an indication that the film inspector noticed either blurred copy because of movement during exposure, or duplicate copy. Unless we meant to delete copyrighted materials that should not have been filmed, you will find a good image of the page in the adjacent frame.

3. When a map, drawing or chart, etc., is part of the material being photographed the photographer has followed a definite method in "sectioning" the material. It is customary to begin filming at the upper left hand corner of a large sheet and to continue from left to right in equal sections with small overlaps. If necessary, sectioning is continued again-beginning below the first row and continuing on until complete.

4. For any illustrations that cannot be reproduced satisfactorily by xerography, photographic prints can be purchased at additional cost and tipped into your xerographic copy. Requests can be made to our Dissertations Customer Services Department.

5. Some pages in any document may have indistinct print. In all cases we have filmed the best available copy.

\section{University Microfilms International}


1921976

OTTENWELIER, JOHN EDWARD

EXTRAPITUITARY REGULATION OF THE CIRCADIAN

RHYTHM OF PLASMA CORTICOSTEROIO CONCENTRATION

IN RATB,

THE LOUISIANA STATE UNIVERBITY AND

AGRICULTURAL AND MECHANICAL COL., PH.D., 1979

University

Microfilms

International 300 N. ZEEB ROAO. ANN ARBOR, MI 48106 
EXTRAPITUITARY REGULATION OF THE CIRCADIAN RHYTHM

OF PLASMA CORTICOSTEROID CONCENTRATION IN RATS

A Dissertation
Submitted to the Graduate Faculty of the Louisiana State University and Agricultural and Mechanical College in partial fulfillment of the requirements for the degree of Doctor of Philosophy
in

The Department of Zoology and Physiology

by

John Edward Ottenweller

B.S., Louisiana State University, 1971

M.S., Louisiana State University, 1975

May 1979 


\section{ACKNOWLEDGMENTS}

I am grateful for the encouragement and guidance of Dr. Albert $H$. Meier, without whom the quality of my research and this dissertation would have been much less. Thanks also to Drs. J.P. Woodring, John J. Wille, Edward N. Lambremont, and R.S. Allen for their helpful comments in review of this manuscript. Thanks to all my fellow graduate students for their assistance in these studies, especially Albert C. Russo, Nelson H. Horseman, and Blaine R. Ferrell, and their provocative discussions. I am especially grateful to Rosemary, my wife, whose long-term support and encouragement have made my education and research possible. 
Acknowledgments

List of Tables

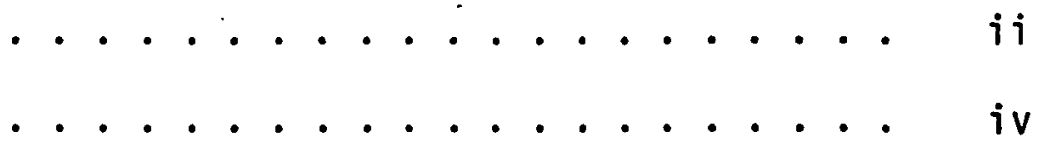

List of Figures

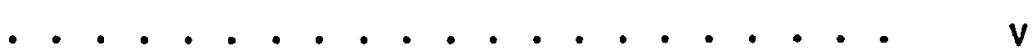

Abstract

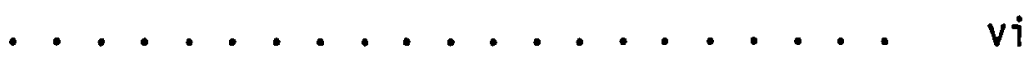

General Introduction

Experiment I.

Effect of Nembutal and Atropine on Plasma Corticosteroid Rhythms of Intact Rats and Hypophysectomized Rats Impianted with Adrenocorticotropin and Thyroxin. . . .

Experiment II.

Daily Rhythm of Adrenocortical Responsiveness to Exogenous ACTH in Hypophysectomized Male Rats............

Experiment III. Circadian Rhythms of Plasma Corticosterone Binding Activity and Plasma Corticosteroid Concentration in Male Rats. ......

Experiment IV. Adrenal Innervation and the Daily Rhythm of Plasma Corticosteroid Concentration in Female Rats...........

Experiment V. Disruption of Adreneal Innervation Abolishes the Plasma Corticosteroid Rhythm and the Daily Variation of Adrenocortical Responsiveness to ACTH in Male Rats .. 65

General Discussion ............. 80

Literature Cited .............. . . 90

Vita 


\section{LIST OF TABLES}

TABLES

Page

TABLE 1. Experimental protocol ........... 35

TABLE 2. Plasma testosterone and thyroxin concentrations

in hypophysectomized rats following injections

of LH and TSH at the onset and offset of light. . . 40 


\section{LIST OF FIGURES}

FIGURES

Page

FIGURE 1. Daily rhythm of plasma corticosteroid concentration in hypophysectomized rats . . . . 12

FIGURE 2. Effect of experimental regime on plasma corticosteroid concentrations at 1800 . . . . . 14

FIGURE 3. Effect of Nembutal on plasma corticosteroid rhythms of intact and hypophysectomized rats. . . 16

FIGURE 4. Effect of atropine on the plasma corticosteroid rhythm in intact rats.......... 18

FIGURE 5. Effect of atropine on the plasma corticosteroid rhythm in hypophysectomized rats. ....... 20

FIGURE 6. Ether stress response in intact and hypophysectomized rats. . . . . . . . . . . . . 22

FIGURE 7. Daily rhythm of plasma thyroxin in intact rats. . . 36

FIGURE 8. Daily variation in adrenocortical responsiveness to ACTH injections in hypophysectomized rats. . . 38

FIGURE 9. Daily rhythms of plasma CBA levals and corticosteroid concentrations in male rats....... 48

FIGURE 10. Daily patterns of plasma corticosteroid concentration in intact female and female rats with autotransplanted adrenal glands....... . 59

FIGURE 11. Ether stress response in intact females and females with adrenal autotransplants....... 61

FIGURE 12. The effect of spinal cord transection on the plasma corticosteroid rhythm. . . . . . . 72

FIGURE 13. Effect of spinal cord transection on daily variations in adrenocortical responsiveness to ACTH. . . 74

FIGURE 14. Ether stress response in intact, T-7 transected, and $L-1$ transected male rats.......... 76

GENERAL DISCUSSION:

FIGURE 15. Diagram of stimulatory and inhibitory pathways which are thought to regulate the plasma corticosteroid rhythm. . . . . . . . . . . . 


\section{ABSTRACT}

A series of experiments is presented which demonstrate extrapituitary regulation of the circadian rhythm of plasma corticosteroid concentration in rats. A circadian rhythm of plasma corticosteroid concentration was present in hypophysectomized male rats implanted with adrenocorticotropin and thyroxin, indicating that the pituitary itself is not essential for this rhythm. The daily rise in plasma corticosteroid concentration at 1800 in hypophysectomized, as well as in intact, rats was suppressed by injection of either Nembutal or atropine at 1200. The plasma corticosteroid rhythm in hypophysectomized rats resulted from a rhythm of adrenocortical responsiveness to ACTH. The rhythm of responsiveness in hypophysectomized rats was phase-shifted by inverting the light-dark cycle. These experiments indicate that neither the pituitary nor a plasma adrenocorticotropin rhythm are essential for setting the phase of the plasma corticosteroid rhythm in rats.

A circadian rhythm of plasma corticosterone binding activity was present in male rats. Although this rhythm may be important in regulating plasma corticosteroid activity during the day, it does not set the phase of the rhythm of plasma corticosteroid concentration. Disruption of adrenal innervation by autotransplanting the adrenal glands of female rats or by spinal cord transection of male rats abolished the plasma corticosteroid rhythms. In addition, spinal cord transection abolished the daily variation of adrenocortical responsiveness to exogenous adrenocorticotropin. These experiments indicate that a rhythm of adrenocortical responsiveness to plasma adrenocorticotropin depends on intact adrenal innervation. A model is proposed whereby a circadian oscillator in 
the hypothalamus controls the plasma corticosteroid rhythm by direct neural pathways between the oscillator and the adrenal gland.

The level of plasma corticosteroid concentration following ether stress was evaluated to assess the roles of plasma adrenocorticotropin and adrenal innervation in the ether stress response. The ether stress response was suppressed in hypophysectomized rats implanted with adrenocorticotropin and thyroxine, in spinal cord transected rats, and in rats with autotransplanted adrenal glands. It is concluded that plasma adrenocorticotropin and adrenal innervation are both necessary for a maximal ether stress response.

vii 
GENERAL INTRODUCTION

The discovery of a daily rhythm of urinary 17-hydroxycorticosterone in man was the first indication of a hormone rhythm (Pincus, 1943). Since that report, much of the research in the area of circadian hormone rhythms has concerned itself with the daily rhythm of plasma corticosteroid concentration. A plasma corticosteroid rhythm was reported first in man (Bliss et al., 1953), and then in rats (Guillemin et al., 1959) and mice (Halberg et al., 1959).

After 1960, the research dealing with the plasma corticosteroid rhythm branched in may directions. The entrainment of the rhythm by the light-dark (LD) cycle has been studied (Critchlow et al, 1963; Holmquest et al, 1966; Scheving and Pauly, 1966; Dunn et al., 1972; Krieger, 1973; Krieger and Hauser, 1978). Other environmental cues which can entrain the rhythm are sleep-wakefulness (restactivity) cycles (Martel et al., 1962; Orth et al., 1967; Gibbs, 1976; Morimoto et al., 1977) and feeding or watering cycles (Johnson and Levine, 1973; Krieger, 1974; Takahashi et al, 1977; Krieger and Hauser, 1978). The development of the rhythm has been studied in young animals (Ader, 1969; Krieger, 1972; Ramaley, 1972; Levin and Levine, 1975; Miyabo and Hisada, 1975; Ottenweller and Meier, 1978).

Since the discovery of daily rhythms of adrenocorticotropin (ACTH) (Ney et al., 1963; Galicich et al., 1965; Nichols and Tyler, 1967; Cheifetz et al., 1968) and corticotropin releasing hormone (CRH) (David-Nelson and Brodish, 1969; Hiroshige and Sakadura, 1971; Takebe et al., 1972; Hiroshige et al., 1973; Hiroshige and Wada-Okada, 1973; 
Sato and George, 1973), much research has centered on the role of the central nervous system in the control of the plasma corticosteroid rhythm. One approach has been to correlate brain neurotransmitter rhythms with plasma corticosteroid rhythms (Dixit and Buckley, 1967; Scapagnini et al., 1971; Simon and George, 1975). Another has been to utilize agonists and antagonists of the neurotransmitters to affect the rhythm (Krieger et al., 1968; Krieger and Rizzo, 1969; Hodges and Mitchley, 1970; Ulrich and Ywiler, 1973; Meier and Srivastava, 1975; Ferrari et al., 1977; Rotsztejn et al., 1977). Yet another approach has been to examine the effect of brain lesions on the rhythm (Moore and Quavi, 1971; Moore and Eichler, 1972; Bellinger et al., 1976; Phelps et al., 1978).

Demonstrations of a daily rhythm of ACTH in adrenalectomized rats (Cheifetz et al., 1968) and a daily rhythm of CRH in both adrenalectomized rats (Hiroshige and Sakakura, 1971) and hypophysectomized rats (Takebe et al., 1972) encouraged the assumption that a daily rhythm of CRH produces a rhythm of ACTH which in turn drives the plasma corticosteroid rhythm (Krieger, 1977). This assumption was challeged by reports of daily rhythms of plasma corticosteroid concentration in hypophysectomized animals that lacked ACTH rhythms (Srivastava and Meier, 1972; Meier, 1976). Other research which suggested that corticosteroid production was influenced by other factors in addition to plasma ACTH concentration has been reported and largely ignored (Voigt, 1944; Ungar and Halberg, 1962; Andrews and Folk, 1963; Ungar, 1963; Urquhart, 1965; Kovach et al., 1970; L'Age et al., 1970; Ventura et al., 1977; Dallman et al., 1978).

The demonstration that plasma corticosteroid rhythms are not 
dependent on plasma ACTH rhythms has raised the question of how the daily rhythm of plasma corticosteroid concentration is controlled. This dissertation presents the results of a series of experiments designed to answer this question and others concerning the plasma corticosteroid rhythm in the rat. Experiment I examined the plasma corticosteroid rhythm in hypophysectomized rats implanted with ACTH and thyroxin and also the effects of Nembutal and atropine on this rhythm. Experiment II examined the possibility of a rhythm of adrenocortical responsiveness to $\mathrm{ACTH}$ in hypophysectomized rats, and whether the phase of such a rhythm could be entrained by the LD cycle. Experiment III involved measuring plasma corticosterone binding activity throughout the day in intact rats. Experiment IV examined the possibilities of neural or humoral control of the plasma corticosteroid rhythm by autotransplanting the adrenal glands of female rats. Experiment $V$ utilized spinal cord transection to study the role of adrenal innervation in the rhythms of plasma corticosteroid concentration and adrenocortical responsiveness to ACTH. Experiments I, IV, and $V$ also examined the roles of plasma ACTH and adrenal innervation in the plasma corticosteroid response to ether stress.

The results of Experiments II and IV have been published (Ottenweller et al., 1978). After publication of Ottenweller et al., other papers relevant to these results have been published and are discussed in this dissertation. It should be kept in mind that my research is not a replication of their work, but rather that their research comes after my work and supports it. 


\section{EXPERIMENT I}

EFFECT OF NEMBUTAL AND ATROPINE ON PLASMA CORTICOSTEROID RHYTHMS

OF INTACT RATS AND HYPOPHYSECTOMIZED RATS

IMPLANTED WITH ADRENOCORTICOTROPIN AND THYROXIN 


\section{INTRODUCTION}

Daily rhythms of plasma corticosteroid concentration are present in hypophysectomized Gulf killifish (Srivastava and Meier, 1972) and hypophysectomized male rats implanted with beeswax pellets containing adrenocorticotropin (ACTH) and thyroxin $\left(T_{4}\right)$ (Meier, 1976). ACTH is required for adrenal regeneration in hypophysectomized rats, and $T_{4}$ is required for the expression of circadian rhythms which are related to the plasma corticosteroid rhythm (Meier, 1976). Meier's experiments demonstrated that the plasma corticosteroid rhythm is not dependent on a plasma ACTH rhythm and that the plasma corticosteroid rhythm in hypophysectomized animals could be phase-shifted by inverting the lightdark (LD) cycle. Inasmuch as the research with rats is the basis of this dissertation and Krieger (personal communication) could not duplicate Meier's results, hypophysectomized male rats were implanted with ACTH and $T_{4}$ to confirm Meier's results.

The experimental regime differed from Meier's only in that the amounts of ACTH and $T_{4}$ in the pellets were increased to insure the persistence of the plasma corticosteroid rhythm for a longer period and thereby allow the assessment of the effects of Nembutal and atropine on this rhythm. These anticholinergic drugs prevent the daily rise of plasma corticosteroid concentration in cats (Krieger and Rizzo, 1968) and Gulf killifish (Meier and Srivastava, 1975), if injected at specific times of day. The effects of Nembutal and atropine on the daily rise of plasma corticosteroid concentration were tested in intact rats and hypophysectomized rats implanted with ACTH and $T_{4}$.

Elevation of plasma corticosteroid concentration following ether 
stress (Cann et al., 1965; Zimmerman and Critchlow, 1967) occurs even if the plasma corticosteroid rhythm has been abolished by frontal deafferentation of the hypothalamus in rats (Halasz et al., 1967) and pigeons (Bouille et al., 1975). The ether stress response is believed to be mediated by release of CRH from the hypothalamus (Sato et al., 1975) and subsequent elevation of plasma ACTH concentration (Allen et al., 1975). To test this hypotheses, both intact rats and hypophysectomized rats implanted with $A C T H$ and $T_{4}$ were subjected to an ether stress test. 


\section{MATERIALS AND METHODS}

Hypophysectomized young mature male Charles River (CD stain) albino rats $(150-200 \mathrm{~g})$ were placed on a $12 \mathrm{~L}: 120$ regime (onset of light: 0600 ) for two weeks. In addition a group of similar intact rats were acclimated to this photoperiod. Purina rat chow and water were available ad libitum. Blood samples were drawn by tail clip at 1800 from all rats at the end of this period. On the following day and three days later, $300 \mu \mathrm{g} \mathrm{ACTH} \mathrm{(88} \mathrm{IU/mg)} \mathrm{in} 0.5 \mathrm{ml}$ saline $(0.9 \% \mathrm{NaCl})$ was injected subcutaneously (s.c.) into the hypophysectomized rats. One week after the second ACTH injection, $0.15 \mathrm{~g}$ beeswax pellets containing $1.5 \mathrm{mg} \mathrm{ACTH}$ and $150 \mu \mathrm{g} \mathrm{T}_{4}$ were implanted s.c. into hypophysectomized rats under light ether anesthesia. On the fourth day after implantation, blood samples were drawn by tail clip at 0600 and 1800 (onset and offset of light) from both hypophysectomized and intact rats.

The next day half of the hypophysectomized and intact rats were injected intraperitoneally with $40 \mathrm{mg}$ Nembutal (sodium pentabarbital) per $\mathrm{kg}$ body weight ( $/ \mathrm{kg} \mathrm{B.W.)}$ at 1200 , and the other half received 0.5 $\mathrm{ml}$ saline. All rats in both groups were sampled by tail clip at 1100 and 1800. The following day the experimental and control groups were reversed, and the same procedure was repeated except that $10 \mathrm{mg}$ atropine sulfate/kg B.W., rather than Nembutal, was injected s.c. at 1200.

On the day following the atropine study, an ether stress test was performed at 1000 on six hypophysectomized and six intact rats. A prestress blood sample was drawn by tail clip at 1000, and the rats were exposed to an ether-saturated atomosphere for 30 seconds at this time. A post-stress blood sample was drawn by tail clip one hour after the 
ether exposure (1100).

The plasma was separated immediately from all blood samples by centrifugation and stored at $-22^{\circ}$ until assayed for corticosteroid concentration. Plasma corticosteroid concentration was assayed by a modification of the competitive protein binding procedure (Murphy, 1969). Duplicate 10 ul samples were extracted with $1.0 \mathrm{ml}$ absolute ethanol, and the ethanol extracts were dried under air at $45^{\circ}$. A standard curve, containing $0.0,0.5,1.0,2.0$, and $3.0 \mathrm{ng}$ corticosterone in $0.5 \mathrm{ml}$ absolute ethanol, was prepared in triplicate and also dried. One ml CBG-solution; containing $1.0 \%$ male human plasma and $0.04 \mu \mathrm{Ci}$ tritiated corticosterone (47.5 Ci/mmol) in distilled water, was added to all assay tubes. The tubes were shaken for 15 seconds using a vortex stirrer and then incubated in a $45^{\circ}$ water bath for 5 minutes. The tubes were then removed from the water bath, shaken for 15 seconds, and transferred to a $4^{\circ}$ water bath for 30 minutes. At the end of this cold incubation, $30 \mathrm{mg}$ Florisil was added to each tube and the tubes were shaken for $30 \mathrm{sec}-$ onds. After the Florisil had settled, a $0.5 \mathrm{ml}$ aliquot was removed from each tube and added to $5.0 \mathrm{ml}$ liquid scintillation fluid containing $0.4 \% \mathrm{p}$-terphenyl and $33 \%$ Triton $\mathrm{X}-100$ in spectrograde toluene.

The samples were counted to $2 \%$ error on a Beckman LS-8000, and the mean $\mathrm{cpm}$ 's for replicates were expressed as a per cent of the $\mathrm{cpm}$ 's in the zero tubes of the standard curve. A standard curve of per cent of zero value versus ng corticosterone was used to estimate the amount of corticosteroid in the samples, and the plasma corticosteroid concentrations were expressed as ug per $100 \mathrm{ml}$ plasma $(\mu \mathrm{g} \%)$. The extraction efficiency was approximately $100 \%$. The limit of detectability was 2.0 $\mu \mathrm{g} \%$, and values which fell below this were assigned concentrations of 
$0.0 \mu \mathrm{g} \%$. The intra-assay variability was $3 \%$, and the inter-assay variability was $5 \%$. Plasma samples that were rerun always fell within $10 \%$ of the original determination.

The data for these studies were analyzed using Student's $\underline{t}$ tests (Snedecor and Cochran, 1967). 


\section{RESULTS}

The hypophysectomized rats had no detectable plasma corticosteroids at 1800 before implanting $A C T H$ and $T_{4}$, indicating that the hypophysectomies were successful. Four days after implanting ACTH and $\mathrm{T}_{4}$, the plasma corticosteroid concentrations in these rats at 1800 were greater than those at $0600(P<0.001)(F i g .1)$, demonstrating the presence of a plasma corticosteroid rhythm in these rats.

Plasma corticosteroid concentration at 1800 in intact rats was not significantly affected by prior sampling alone or prior sampling and saline injection (Fig. 2). Therefore the rhythm was not affected by the experimental regime used to test the effects of Nembutal and atropine on it. However, Nembutal injection at 1200 blocked the daily rise of plasma corticosteroid concentration at 1800 in both intact rats and hypophysectomized rats implanted with ACTH and $T_{4}$ (Fig. 3). Nembutal injection decreased the rise in plasma corticosteroid concentration from 1100 to 1800 as compared with saline injections $(P<0.01)$. This decrease was the result of lower concentrations at $1800(P<0.05)$ and not higher concentrations at 1100.

Injections of $10 \mathrm{mg} / \mathrm{kg} \mathrm{B.W.} \mathrm{atropine} \mathrm{sulfate,} \mathrm{but} \mathrm{not} 1.0 \mathrm{mg} / \mathrm{kg}$ B.W., also blocked the daily rise of plasma corticosteroid concentration from 1100 to 1800 in intact rats (Fig. 4). Although the lower dose was ineffective, the higher atropine dose decreased the rise in concentration from 1100 to $1800(P<0.01)$ and lowered the concentration at $1800(P<0.05)$ as compared with saline injection. Injection of $10 \mathrm{mg} / \mathrm{kg} \mathrm{B.W.} \mathrm{atropine} \mathrm{sulfate} \mathrm{also} \mathrm{blocked} \mathrm{the} \mathrm{daily} \mathrm{rise} \mathrm{of} \mathrm{plasma}$ corticosteroid concentration from 1100 to 1800 in hypophysectomized 
rats implanted with $\mathrm{ACTH}$ and $\mathrm{T}_{4}$ (Fig. 5). Atropine injections again decreased the rise in plasma corticosteroid concentration from 1100 to $1800(P<0.01)$ and lowered the concentrations at $1800(P<0.01)$ as compared with saline injections.

Plasma corticosteroid concentrations one hour after ether stress were greater than pre-stress concentrations in intact rats $(P<0.01)$, but this ether stress response was suppressed in hypophysectomized rats implanted with $\mathrm{ACTH}$ and $T_{4}$ (Fig. 6). 
Figure 1. Daily rhythm of plasma corticosteroid concentration in hypophysectomized rats. Blood samples drawn at 0600 and 1800 four days after implanting ACTH and $T_{4}$. 12L:12D regime (onset of light: 0600). Ten animals per group. 


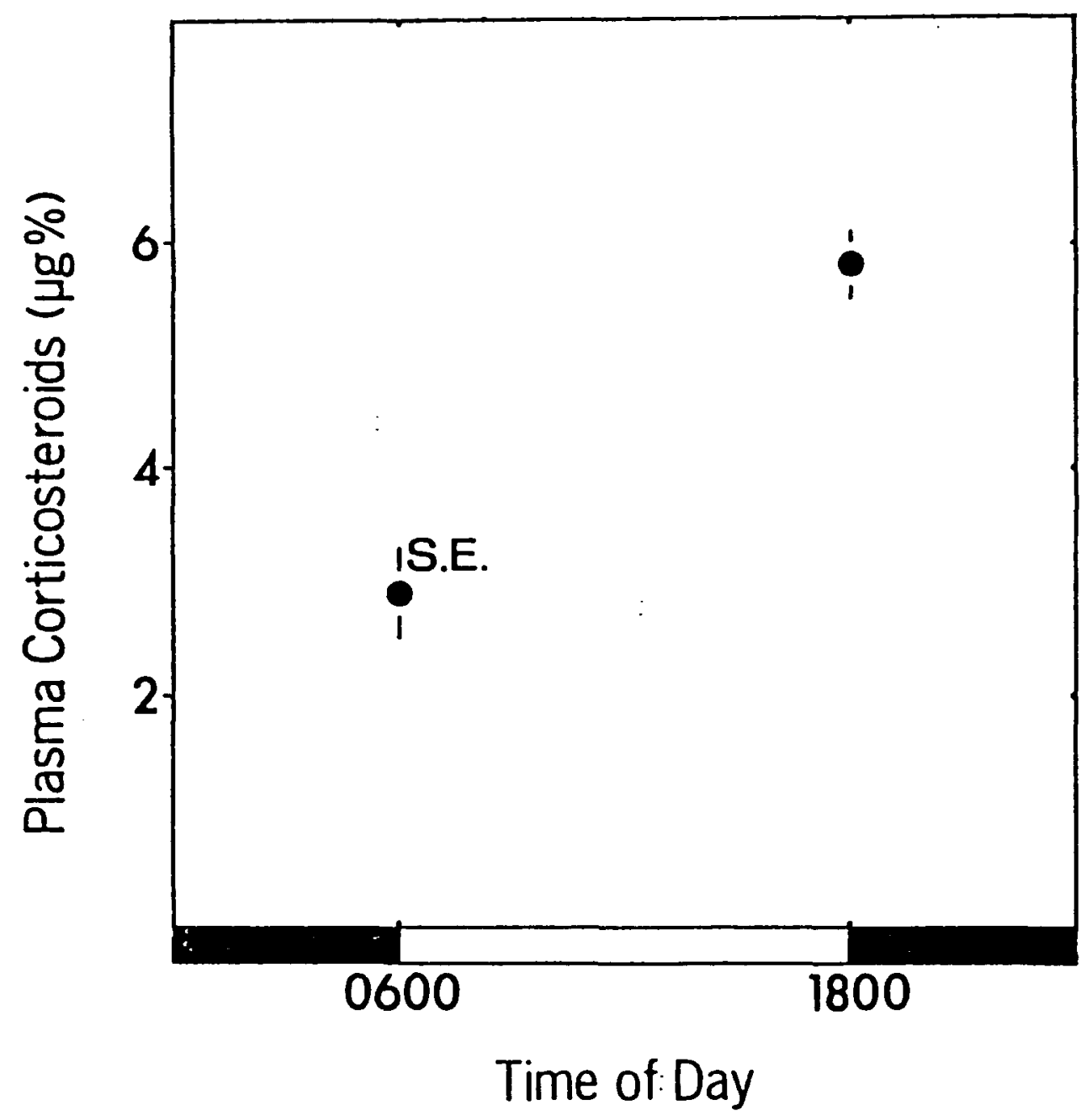


Figure 2. Effect of experimental regime on plasma corticosteroid concentrations at 1800 . Intact male rats were sampled at 1800 only, sampled at both 1100 and 1800 , or sampled at 1100, injected with saline at 1200, and sampled at 1800. 12L:12D regime (onset of light: 0600 ). Six animals per group. 


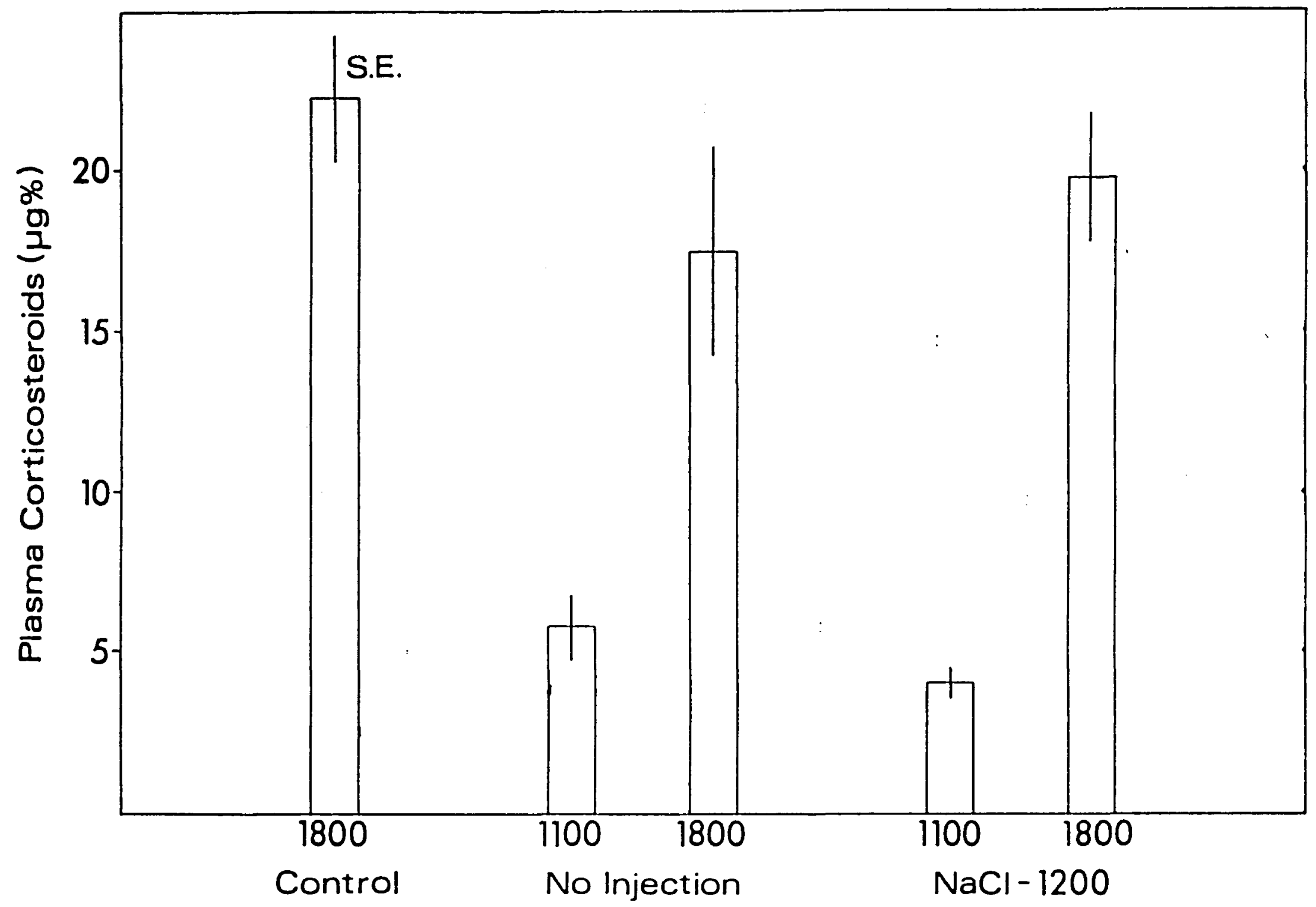


Figure 3. Effect of Nembutal on plasma corticosteroid rhythms of intact and hypophysectomized rats. Saline $(0.5 \mathrm{ml})$ and Nembutal (40 mg/kg B.W.) were injected at 1200 in intact male rats and hypophysectomized male rats implanted with ACTH and $T_{4}$. Blood samples were drawn at 1100 (AM) and 1800 (PM). 12L:120 regime (onset of light: 0600). Five or six animals per group. 
$=$

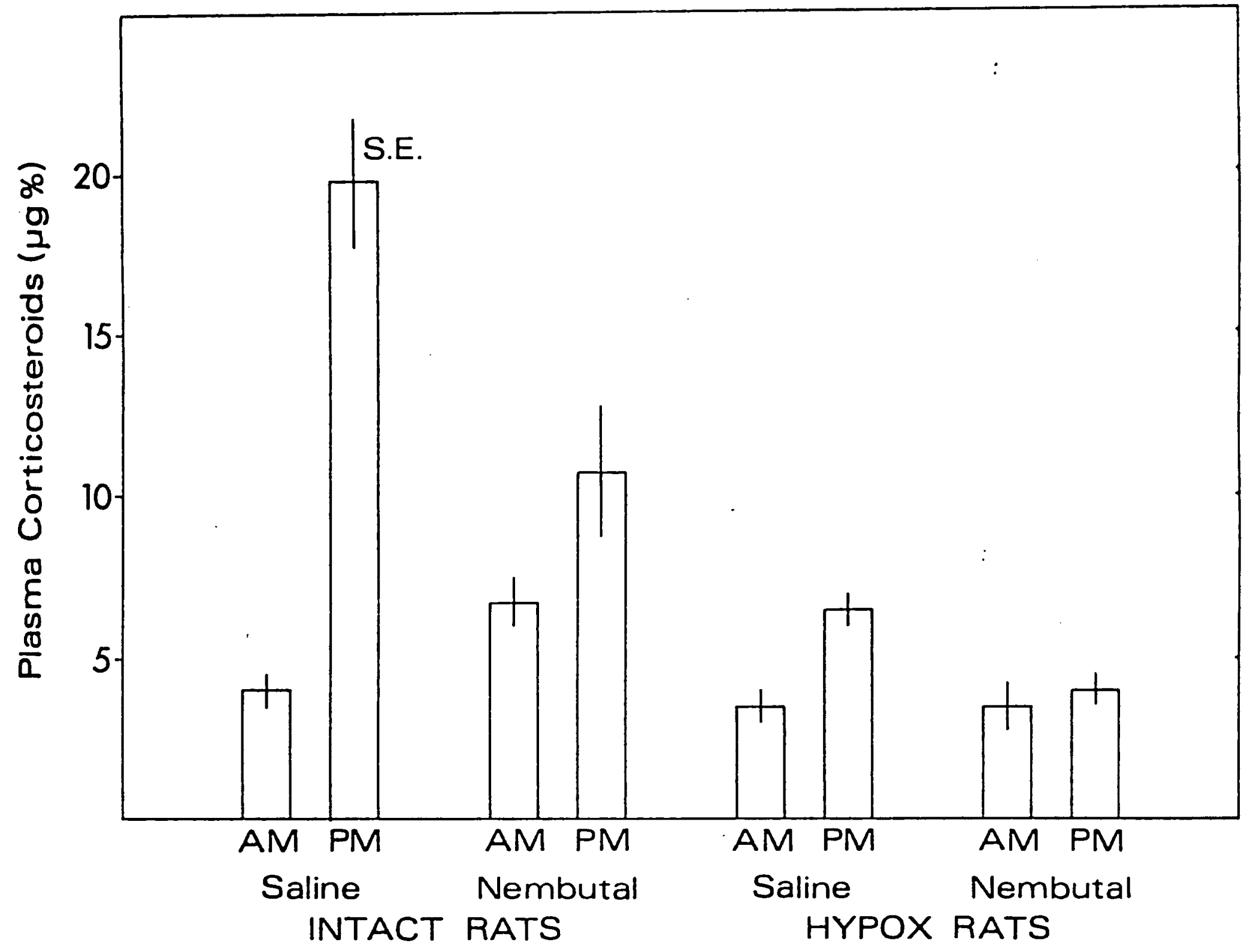


Figure 4. Effect of atropine on the plasma corticosteroid rhythm in intact rats. Intact male rats were injected at 1200 with saline $(0.5 \mathrm{ml}), 1.0 \mathrm{mg} / \mathrm{kg}$ B.W. atropine sulfate, or 10 $\mathrm{mg} / \mathrm{kg}$ B.W. atropine sulfate. Blood samples were drawn at 1100 (AM) and 1800 (PM). 12L:120 regime (onset of 1ight: 0600). Six animals per group. 





Figure 5. Effect of atropine on the plasma corticosteroid rhythm in hypophysectomized rats. Hypophysectomized male rats implanted with ACTH and $T_{4}$ were injected at 1200 with saline $(0.5 \mathrm{ml})$ or atropine sulfate $(10 \mathrm{mg} / \mathrm{kg}$ B.W. $)$. Blood samples were drawn at 1100 (AM) and 1800 (PM). 12L:120 regime (onset of light: 0600). Five or six animals per group. 


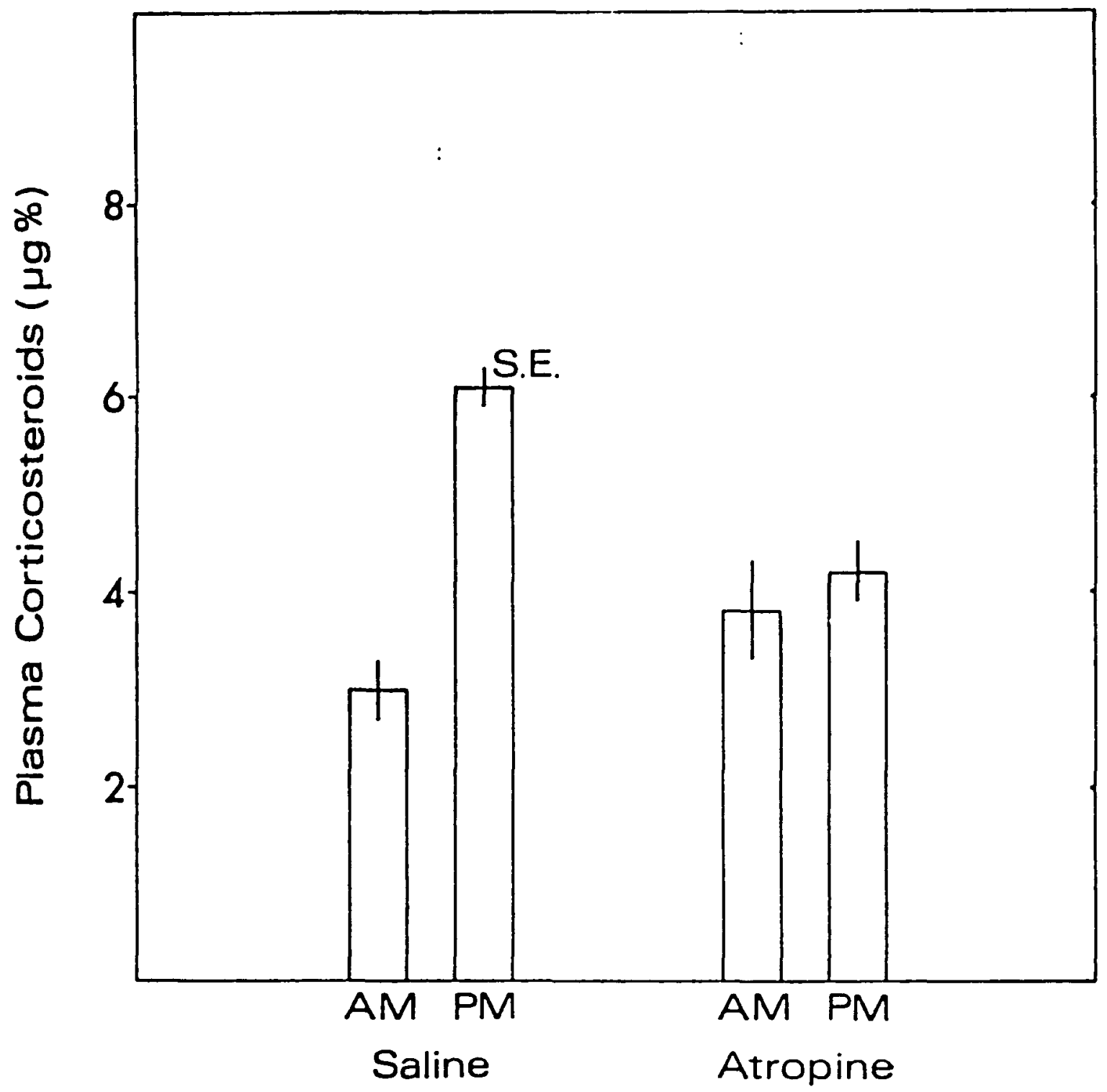


Figure 6. Ether stress response in intact and hypophysectomized rats. Blood samples were drawn before (Pre) and one hour after (Post) ether exposure at 1000 of intact male rats and hypophysectomized male rats implanted with ACTH and $T_{4}$. 12L:12D regime (onset of light: 0600). Six animals per group. 


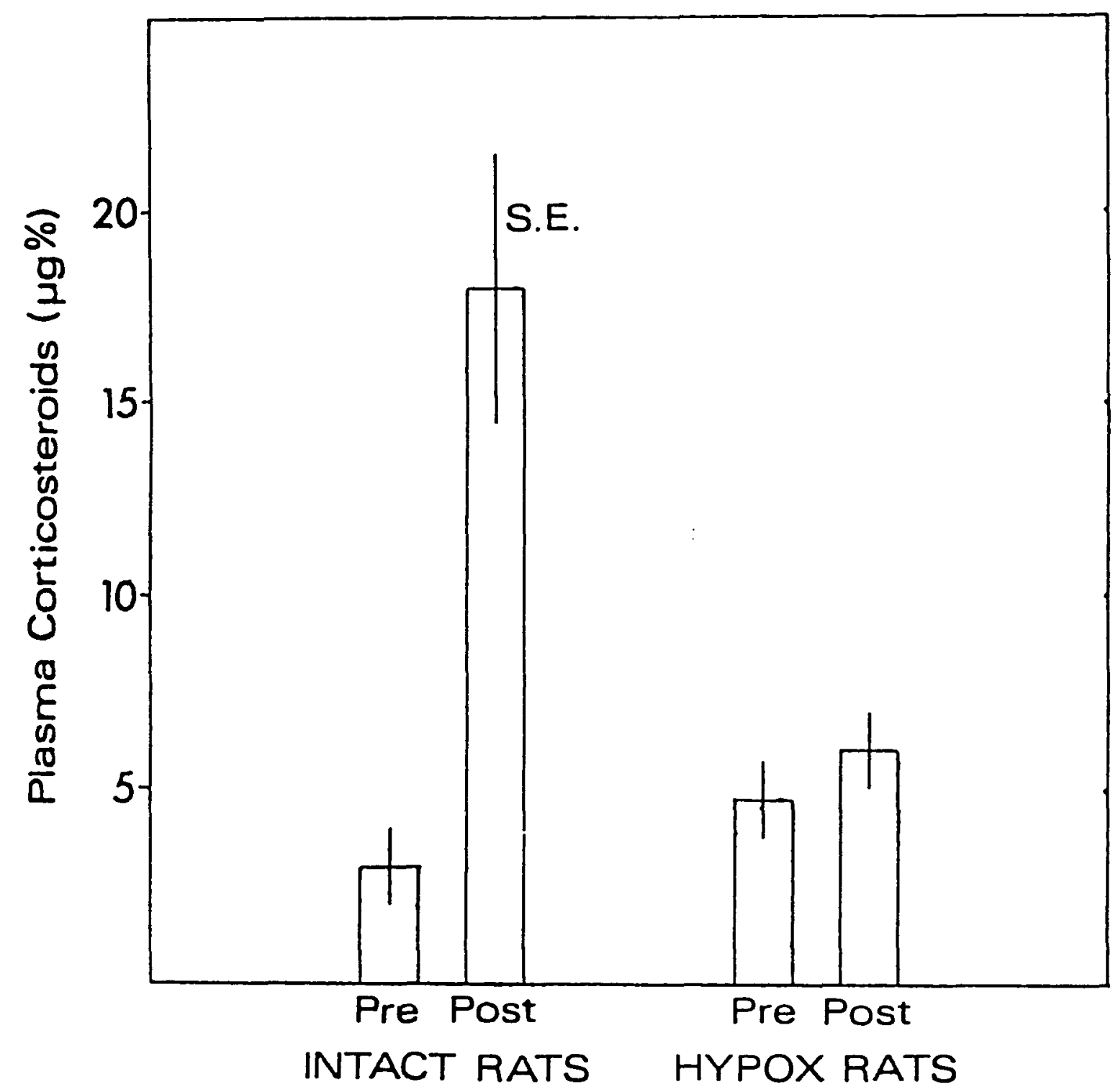




\section{DISCUSSION}

Daily rhythms of plasma corticosteroid concentration have been reported many times in the rats with the peak concentration at the offset of light and the trough at the onset of light (Guillemin et al., 1959; McCarthy et al., 1960; Critchlow et al., 1963; Scheving and Pauly, 1966). The corticosteroid rhythm is not dependent on rhythmic release of ACTH from the pituitary in either fish or rats (Srivastava and Meier, 1972; Meier, 1976). These studies demonstrated that the plasma corticosteroid rhythm in hypophysectomized animals could be phase-shifted by inverting the LD cycle, indicating that the pituitary gland is not required to set the phase of the rhythm.

The present study confirms the presence of a plasma corticosteroid rhythm in hypophysectomized rats implanted with $A C T H$ and $T_{4}$ (Meier, 1976). This rhythm was present on three consecutive days in the same animals (controls for Nembutal and atropine studies). These results again indicate that rhythmic release of ACTH by the pituitary is not required for the plasma corticosteroid rhythm. It has been suggested that a daily rhythm of adrenocortical responsiveness to plasma ACTH is involved in setting the phase of the plasma corticosteroid rhythm (Ottenweller et al., 1978; Dallman et al., 1978). Inasmuch as a plasma corticosteroid rhythm occurs in the presence of constant plasma ACTH concentrations during the day in hypophysectomized rats implanted with ACTH and $T_{4}$ (Meier, 1976; the present study), the plasma corticosteroid rhythm in hypophysectomized rats must be the result of a daily rhythm of adrenocortical responsiveness to plasma ACTH.

Timed injections of either Nembutal or atropine, which are 
anticholinergic drugs, abolish the daily rhythm of plasma corticosteroid concentration in cats (Krieger et al., 1968) and fish (Meier and

Srivastava, 1975). The present study demonstrates that these drugs have the same effect in both intact rats and hypophysectomized rats implanted with ACTH and $T_{4}$. Because these drugs abolish the plasma corticosteroid rhythm in hypophysectomized rats, their effect on the rhythm must be independent of an effect on ACTH release from the pituitary.

That hypophysectomized rats respond to anticholinergic drugs in the same manner as intact rats suggests that similar mechanisms are responsible for the phases of the plasma corticosteroid rhythms in both groups. This is particularly important for two reasons. First, it means that manipulation of central nervous system function, by such means as lesioning or drug administration (Moore and Eichler, 1972; Krieger and Rizzo, 1969), may affect the plasma corticosteroid rhythm without necessarily affecting ACTH secretion by the pituitary. Secondly, hypophysectomized rats implanted with $\mathrm{ACTH}$ and $\mathrm{T}_{4}$ may be a good model for studying the control of the plasma corticosteroid rhythm without the complication of the plasma ACTH rhythm present in intact rats.

Elevation of plasma corticosteroid concentration in repsonse to ether stress (ether stress response) depends on the integrity of the posterior hypothalamic area in rats, whereas the plasma corticosteroid rhythm depends on anterior hypothalamic areas (Slusher, 1964; Halasz et al., 1967; Palka et al., 1969). These experiments indicate that separate mechanisms regulate the plasma corticosteroid rhythm and the ether stress response, and the present study confirms this. Although some stress responses may not require the presence of the pituitary gland (Ventura et al., 1977), the results of the present study indicate 
that release of ACTH from the pituitary is required for a maximal ether stress response.

Two mechanisms may explain the daily rhythms of plasma corticosteroid concentration and adrenocortical responsiveness to plasma ACTH in the absence of the pituitary and a plasma ACTH rhythm. One mechanism involves the regulation of adrenal blood flow. Adrenal blood flow affects corticosteroid secretion (Bush, 1953; Urquhart, 1965; L'Age et al., 1970), and hypothalamic stimulation of hypophysectomized dogs alters adrenal blood flow and corticosteroid secretion in a similar manner (Kovach et al., 1970). Because both ACTH and transcortin stimulate corticosteroid production in vitro (Ungar, 1963; Makoff et al., 1964), the daily rhythm of adrenocortical responsiveness may be the result of a rhythm in the rate of adrenal blood flow which may affect the exposure of adrenocortical cells to plasma ACTH or transcortin.

A second possible mechanism involves control of adrenocortical responsiveness by direct innervation of the steroidogenic cells of the adrenal cortex, which are innervated by cholinergic nerve fibers (Unsicker, 1971; Unsicker et al., 1977). The possibility that this innervation may alter adrenocortical responsiveness to plasma ACTH was enhanced by the fact that anticholinergic drugs abolished the plasma corticosteroid rhythm in hypophysectomized animals in the present study. However, it should be noted that the action of these drugs may have been at the level of the central nervous system and not the adrenal gland. The two mechanisms presented here may act alone, or in conjection with other factors, to produce a daily rhythm of adrenocortical responsiveness to plasma ACTH which drives the plasma corticosteroid rhythm. 


\section{EXPERIMENT II}

DAILY RHYTHM OF ADRENOCORTICAL RESPONSIVENESS TO EXOGENOUS ACTH IN HYPOPHYSECTOMIZED MALE RATS 


\section{INTRODUCTION}

A daily rhythm of plasma corticosteroid concentration was present in hypophysectomized rats implanted with adrenocorticotropin (ACTH) and thyroxin $\left(T_{4}\right)$ (Meier, 1976; Exp. I), and this rhythm was phase-shifted by inverting the light-dark (LD) cycle (Meier, 1976). Timed injections of anticholinergic drugs abolished this rhythm in hypophysectomized rats as in intact rats (Exp. I).

The assumption was made in both Meier's study and Exp. I that the pellets maintain plasma $A C T H$ and $T_{4}$ concentrations at a constant level during the day. Because locomotor activity increases the rate of lymphatic return to the blood vascular system (Guyton, 1976), the greater plasma corticosteroid concentration at the onset of darkness (beginning of locomotor activity) could have been the consequence of greater ACTH concentrations that accompany increased iymphatic flow from the pellets to the blood vessels at this time. The present study measured plasma corticosteroid concentrations in hypophysectomized rats in response to intracardial injections of ACTH at the onset and offset of 1 ight to determine if a rhythm of response to ACTH injections existed in these animlas and if such a rhythm could be phase-shifted by inverting the LD cycle. In addition, the response of plasma androgen and $T_{4}$ to injections of leuteinizing hormone (LH) and thyroid stimulating hormone (TSH) was examined in a similar manner. 


\section{MATERIALS AND METHODS}

Hypophysectomized young mature Charles River (CD strain) albino male rats $(150-200 \mathrm{~g})$ were placed on a $12 \mathrm{~L}: 12 \mathrm{D}$ regime (onset of light: 0600) with Purina rat chow and water available ad libitum. The rats were sampled at 1800, and the plasma samples contained no detectable corticosteroids. This fact, in conjunction with the absence of significant increases in body weight and small testes, indicated the success of the hypophysectomies.

The rats were treated in preparation for this study with ACTH, TSH, human chorionic gonadotropin ( $h C G$ ), and pregnant mare serum (PMS) to increase the responsiveness of the adrenal cortex, thyroid, and testes. Each preparatory injection contained 0.05 IU ACTH, 0.2 TSH, $0.25 \mathrm{U}$ hCG, and $10.0 \mathrm{U}$ PMS in $0.2 \mathrm{mi} 0.9 \% \mathrm{NaCl}$ and was administered subcutaneous ly. Each rat received 9 or 10 preparatory injections before day 6 , when the experimental injections were given. The light-dark (LD) cycle was inverted on day 7, and 5 or 6 additional preparatory injections were administered before experimental injections on day 12 . The experimental injections contained $0.5 \mathrm{IU}$ ACTH, $0.5 \mathrm{TSH}$, and $125 \mu \mathrm{g} \mathrm{LH}$ in $0.1 \mathrm{ml} 0.9 \%$ $\mathrm{NaCl}$ and were administered intracardially. See Table 1 for a summary of the injection schedule.

The times of both preparatory and experimental injections were carefully chosen. The injections were made at the onset and offset of the daily photoperiod. The onset of light is the time of low plasma corticosteroid concentration whereas concentrations are high at the offset of light (Guillemin et al., 1959; Critchlow et al., 1963). A daily rhythm of plasma $T_{4}$ concentration was measured in the plasma 
samples of Exp. III; the relationship between the concentrations at the onset and offset of light is similar to that of corticosteroids (Fig. 1). In contrast, plasma androgen concentrations are higher at the onset of light than at the offset (Kinson and Liu, 1973; Wilson et al., 1976).

Blood samples were drawn by tail clip immediately before the experimental injections and at one and four hours äfter the injections. The plasma was separated by centrifugation and stored at $-22^{\circ}$ until assayed. Plasma corticosteroid and androgen concentrations were determined in the pre-injection and one hour samples, whereas plasma $T_{4}$ concentrations were determined in pre-injection and four hour samples. The data were analyzed statistically using Student's $\underline{t}$ tests (Snedecor and Cochran, 1967).

Assay Procedures

Corticosteroid concentrations in the plasma samples were assayed by a modification of the competitive protein binding procedure (see Exp. I).

Plasma androgen concentrations were determined by Nelson Horseman using a modification of the competitive protein binding ( $C P B$ ) procedure (Horton et al., 1967). Plasma samples $(25-50 \mu 7)$ were extracted in 100 volumes of absolute ethanol, and the extract was dried under air at $45^{\circ}$. Standard amounts of testosterone $(0-50 \mathrm{pg})$ were prepared in absolute ethanol and also dried. This extraction technique gave high recovery of internal standard $(\sim 100 \%)$ and very low blank values $(<10 \mathrm{pg})$. One ml CPB-solution ( $0.004 \mu \mathrm{Ci}$ tritiated testosterone, $0.3 \%$ third trimester human pregnancy plasma, and $1.0 \%$ gelatin in $0.1 \mathrm{M}$ phospate buffer, $\mathrm{pH}$ 7.4) was added to all tubes. The assay tubes were stirred on a vortex 
mixer and then incubated at $22^{\circ}$ for 15 minutes. At the end of the incubation period, $0.5 \mathrm{ml}$ dextran-coated charcoal solution $10.1 \%$ Norit $\mathrm{A}$ and $0.015 \%$ Dextran $\mathrm{T}-70$ in $0.1 \mathrm{M}$ phosphate buffer, $\mathrm{pH} 7.4$ ) was added to all assay tubes, and the tubes were centrifuged immediately at 2000 $X \mathrm{~g}$ for 5 minutes. A $1.0 \mathrm{ml}$ aliquot of the supernatant was removed and added to $10 \mathrm{ml}$ liquid scintillation fluid $(0.4 \% \mathrm{p}$-terphenyl and $33 \%$ Triton $x-100$ in spectrograde toluene). The samples were counted to $2 \%$ error on a Beckman LS-8000. The androgen concentrations in the plasma samples were estimated from a standard curve of $\mathrm{cpm}$ versus $\mathrm{pg}$ testoster- one and were expressed as $\mathrm{ng} / \mathrm{ml}$.

Plasma $\mathrm{T}_{4}$ concentrations in unextracted plasma were determined by Blaine Ferrell using a radioimmunoassay procedure (Mitsuma et al., 1972). The assay procedure was performed in duplicate in $10 \times 75 \mathrm{~mm}$ disposable glass tubes by the addition of $0.1 \mathrm{ml}$ sample or standard (diluted $1: 2$ in barbital diluent which contained $0.1 \%$ bovine serum albumin in $0.08 \mathrm{M}$ sodium barbital, $\mathrm{pH} 8.4), 0.1 \mathrm{ml}$ isotope solution (50 pg ${ }^{125} \mathrm{I}-\mathrm{T}_{4}$ in barbital diluent), $0.2 \mathrm{ml}$ ANS solution (350 $\mu \mathrm{g}$ 8-anilino-1-napthalene sulfonic acid in barbital diluent), and $0.1 \mathrm{ml} \mathrm{T}_{4}$-antibody solution (antibody diluted 1:100 in barbital diluent). The assay tubes were stirred on a vortex mixer and then incubated for 90 minutes in a $37^{\circ}$ water bath. At the end of this incubation period, the tubes were transferred to a $4^{\circ}$ water bath for 10 minutes, and then $1.0 \mathrm{ml}$ dextrancoated charcoal solution $(0.5 \%$ Norit $A$ and $0.05 \%$ Dextran T-70 in barbital diluent) was added to each tube. The tubes were stirred on a vortex mixer, incubated at $4^{\circ}$ for 20 minutes, and then centrifuged at $1000 \times \mathrm{g}$ for 15 minutes at $4^{\circ}$. A $1.0 \mathrm{ml}$ aliquot of the supernatant was removed and added to $10 \mathrm{ml}$ liquid scintillation fluid (see above). The 
samples were counted to $2 \%$ error on a Beckman LS-8000. $T_{4}$ concentrations in the plasma samples were estimated from a standard curve of cpm versus $\mathrm{pg} \mathrm{T}_{4}$ and expressed as $\mu \mathrm{g}$ per $100 \mathrm{ml}$ plasma ( $\mu \mathrm{g} \%$ ). 


\section{RESULTS}

At the time of the experimental injections on day 6 and 12, there was no detectable $(<2 \mu \mathrm{g} \%)$ costicosteroid in any of the plasma samples. Injections of ACTH at the offset of light on day 6 stimulated an increase of plasma corticosteroid concentration to $14 \pm 2 \mu \mathrm{g} \%$ one hour after injection (2100), but similar injections at the onset of light caused an increase of only $4 \pm 1 \mu g \%$ within one hour (0900) (Fig. 2). The corticosteroid concentration at 2100 was significantly greater than that at $0900(P<0.01)$. Five days after reversal of the LD cycle there was also a reversal in responsiveness to ACTH injections; ACTH injections at the offset of light on day 12 induced greater plasma corticosteroid concentrations $(22 \pm 3 \mu \mathrm{g} \%$ ) than ACTH given at the onset of light $(8 \pm 1 \mu g \%)$ (Fig. 2). These two groups also differ statistically $(P<0.01)$.

Androgen was not detectable at the time of experimental injections on day 6 (LD schedule) nor at the onset of light on day 12 (DL schedule). Low concentrations $(1.1 \pm 0.5 \mathrm{ng} / \mathrm{ml})$ were present at the offset of light on day 12 (Table 2). In contrast to corticosteroid responses to ACTH injections, there was no difference between androgen concentrations after $\mathrm{LH}$ injections at 0600 and 2000 . The increases in plasma androgen one hour after LH..injections ranged from 2.0-2.4 ng/ml for tests made at the onset and offset of light on both LD and DL cycles.

As might have been expected based on the daily rhythm of plasma $\mathrm{T}_{4}$ concentration in intact rats $(P<0.05)$ ( $\left.F i g .1\right)$, plasma $T_{4}$ concentrations were $2.7 \pm 0.7 \mu \mathrm{g} \%$ at the onset of 1 ight and $4.6 \pm 0.7 \mu \mathrm{g} \%$ at the offset of light on the LD cycle (Table 2). However, this difference 
was not statistically significant. On the DL cycle the concentrations were $3.2 \pm 0.7 \mu \mathrm{g} \%$ at the onset of light and $3.0 \pm 0.6 \mu \mathrm{g} \%$ at the offset (day 12). In comparing the responses to injections of TSH made at the onset and offset of light, neither the plasma concentrations four hours after injection nor the increases in concentration from the time of injection varied significantly on either the LD or DL cycles. The results of this study indicate that there are no significant differences in the responses of plasma androgen and thyroxin when the tropic hormones (LH and TSH) are injected at times of day when plasma androgen and thyroxin concentrations are highest and lowest in normal male rats. However, further tests including other times of day for injections would be required to determine whether there are daily variations of responsiveness to TSH and LH in hypophysectomized rats that differed in phase from those found in intact rats. 
Table 1. Experimental protocol.

\begin{tabular}{|c|c|c|c|c|c|c|c|c|c|c|c|c|c|c|c|c|c|c|c|c|c|c|c|c|}
\hline \multirow{2}{*}{$\begin{array}{l}\text { Day } \\
\text { Time }\end{array}$} & \multicolumn{3}{|c|}{1} & \multicolumn{2}{|c|}{2} & 3 & \multicolumn{2}{|c|}{4} & \multicolumn{2}{|c|}{5} & \multicolumn{2}{|c|}{6} & \multicolumn{2}{|r|}{7} & \multicolumn{2}{|c|}{8} & \multicolumn{2}{|c|}{9} & \multicolumn{2}{|c|}{10} & \multicolumn{2}{|c|}{11} & \multicolumn{2}{|c|}{12} \\
\hline & 8 & 20 & 8 & 20 & 8 & 20 & 8 & 20 & 8 & 20 & 8 & 20 & 8 & 20 & 8 & 20 & 8 & 20 & 8 & 20 & 8 & 20 & 8 & 20 \\
\hline Photoperi & 080 & -2 & 2000 & & & & & & & & & & LD & inver & ted & 2000 & - & 800 & & & & & & \\
\hline Group $A^{a}$ & $P$ & $P$ & $P$ & $P$ & $P$ & $P$ & $P$ & $P$ & $P$ & $P$ & $\mathrm{E}^{\mathrm{C}}$ & & & & & & $P$ & $P$ & $P$ & $P$ & $P$ & $P$ & $E$ & \\
\hline Group B & $P$ & $\mathrm{P}$ & $P$ & $P$ & $P$ & $\mathrm{P}$ & $P$ & $\mathrm{P}$ & $\mathrm{P}$ & $P$ & $E$ & & & & & & & $P$ & $P$ & $P$ & $P$ & $P$ & $E$ & \\
\hline Group C & $P$ & $P$ & $P$ & $P$ & $P$ & $\mathbf{P}$ & $P$ & $P$ & $P$ & $P$ & $P$ & $\mathrm{E}$ & & & & & & $P$ & $P$ & $P$ & $P$ & $P$ & $P$ & $E$ \\
\hline Group D & & $p$ & $P$ & $P$ & $P$ & $P$ & $P$ & $P$ & $P$ & $P$ & $P$ & $E$ & & & & & & & $P$ & $P$ & $P$ & $P$ & $P$ & $E$ \\
\hline
\end{tabular}

${ }^{a}$ Each group contained 4 rats.

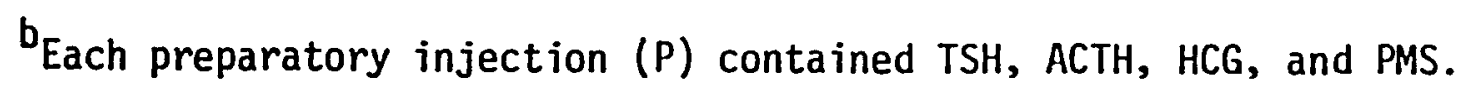

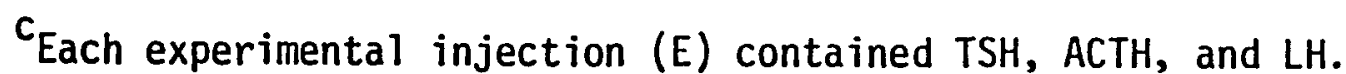


Figure 7. Daily rhythm of plasma thyroxin concentration in intact male rats. 14L:100 regime (onset of light: 0600 ). Six animals per group. 
ติ

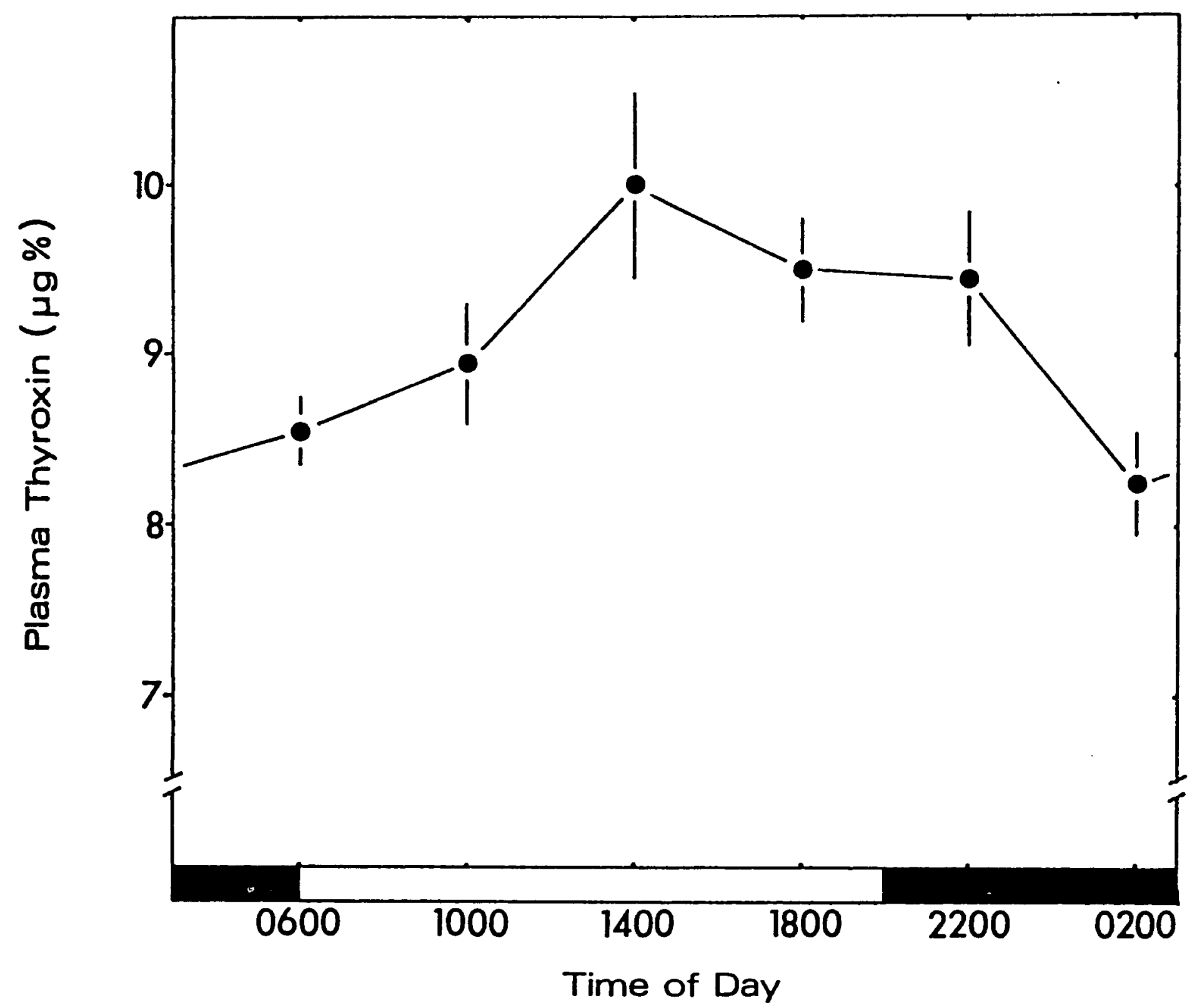


Figure 8. Daily variation in adrenocortical responsiveness to ACTH injections in hypophysectomized rats. Blood was drawn one hour after ACTH injections at the onset and offset of light on a normal (LD) 12L:12D regime (onset of light: 0800 ) and five days after reversal of the LD regime (DL). Eight animals per group. 

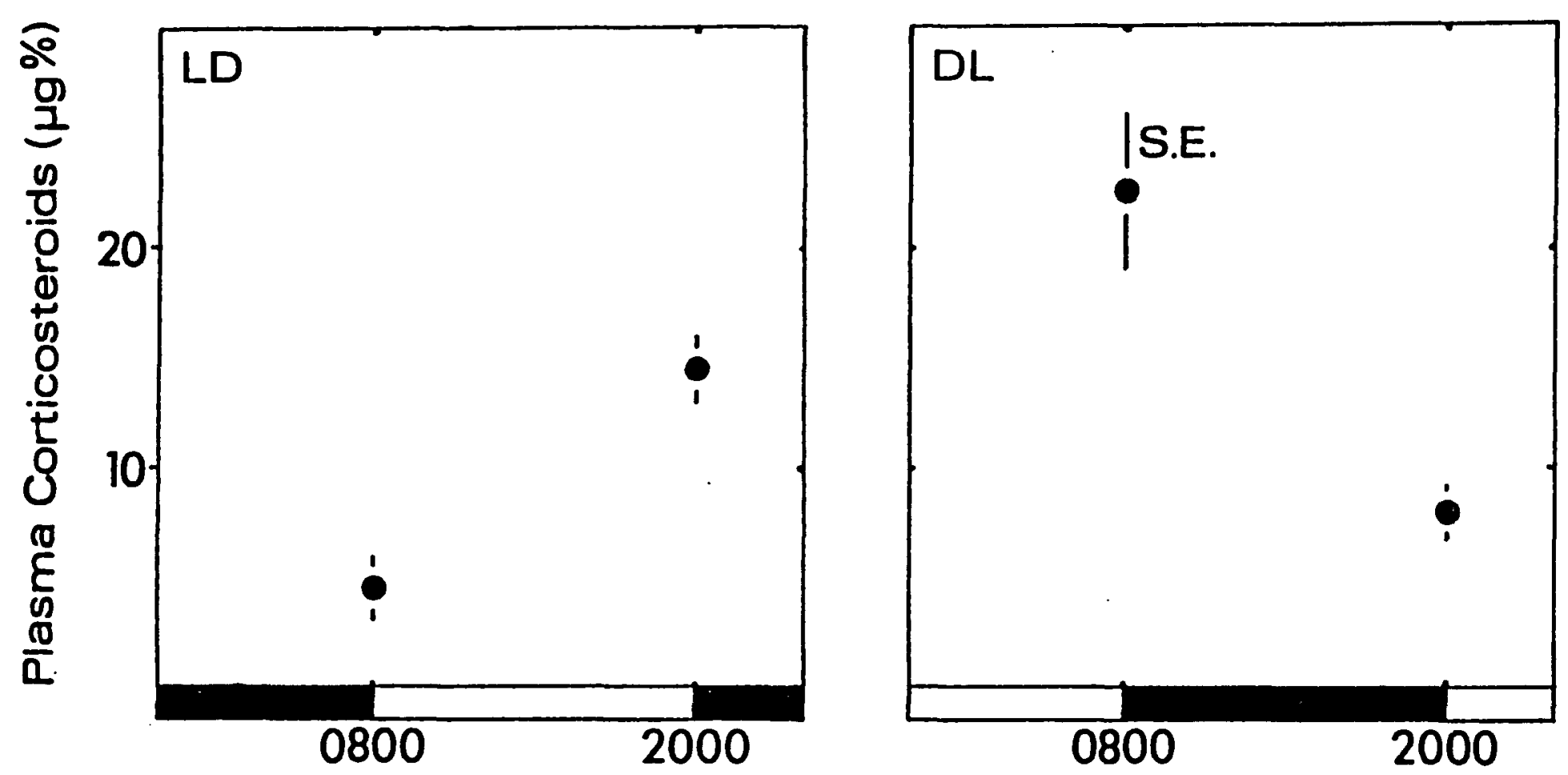

Time of Day 
Table 2. Plasma testosterone and thyroxin concentrations in hypophysectomized rats following injections of LH and TSH at the onset and offset of light.

\begin{tabular}{lllll}
\hline Daily Photoperiod & \multicolumn{2}{c}{ Onset of Light } & \multicolumn{2}{c}{ Offset of Light $^{\mathrm{b}}$} \\
& Before & After $^{\mathrm{d}}$ & Before & After $^{\mathrm{d}}$ \\
LH \& TSH & LH \& TSH & LH \& TSH & LH \& TSH
\end{tabular}

TESTOSTERONE

(ng/ml)

\begin{tabular}{|c|c|c|c|c|}
\hline $\begin{array}{l}\text { Normal } \\
\text { (LD 12:12) }\end{array}$ & N.D. ${ }^{e}$ & $2.2 \pm 0.7(7)^{f}$ & N.D. & $2.0 \pm 0.6(8)$ \\
\hline $\begin{array}{l}\text { Inverted } \\
\text { (DL } 12: 12 \text { ) }\end{array}$ & N.D. & $2.4 \pm 0.6(7)$ & $1.1 \pm 0.5(6)$ & $3.5 \pm 0.2(7)$ \\
\hline
\end{tabular}

THYROXIN

$(\mu g \%)$

Normal

(LD 12:-12)

N.D.

$5.6 \pm 1.7(5)$

$4.6 \pm 0.0(5)$

$6.8 \pm 1.2(5)$

Inverted

(DL 12:12)

$3.2 \pm 0.7(6) \quad 7.4 \pm 0.7(6) \quad 3.0 \pm 0.6(6) \quad 6.6 \pm 1.2(6)$

${ }^{a} 0800$ in the normal LD 12:12 schedule, 2000 in the inverted schedule. $b_{2000}$ in LD, 0800 in DL. .

${ }^{c}$ Immediately before LH and TSH injections.

${ }^{d}$ One hour (testosterone samples) or 4 hours (thyroxin) after injections. $e_{\text {Not detectabie. }}$

$f_{\text {Mean }} \pm$ S.E. (no. of samples). 


\section{DISCUSSION}

This study indicates that intravascular injection of ACTH is approximately three times more effective at the offset than at the onset of light in elevating plasma corticosteroid concentration in hypophysectomized rats. This variation in adrenocortical responsiveness can fully account for the daily rhythm of plasma corticosteroid concentration reported in normal male rats. The ratios of high to low concentrations ( 3.5 on day 6 and 2.8 on day 12) are equivalent to ratios of peak to trough levels of the plasma corticosteroid rhythm in intact rats (Guillemin et al., 1959; Critchlow et al., 1963; Meier, 1976; Exp. I). These results are also in agreement with the ratio of peak to trough levels of the daily rhythm of adrenocortical responsiveness to plasma ACTH in intact rats (Dallman et al., 1978). Although daily rhythms of plasma ACTH (Nichols and Tyler, 1967; Cheifetz et al., 1968; Krieger, 1977) may be expected to contribute toward a plasma corticosteroid rhythm, the present study supports the conclusion that the plasma corticosteroid rhythm does not depend on a driving rhythm of plasma ACTH from the pituitary (Meier, 1976; Dallman et al., 1978, Exp. I).

Because there was no detectable plasma corticosteroid in hypophysectomized rats prior to ACTH injections, it seems clear that the daily variation in adrenocortical responsiveness observed following ACTH injection could not have been a consequence of a periodic fluctuation of engodenous ACTH from a pituitary remnant or from any other source. The possibility of nonsynchronized free running rhythms of adrenocortical activity at the organ level has also been eliminated. The rhythms must have been synchronized with the photoperiod to account for an observable 
rhythm within the group ten months following hypophysectomy and for reentrainment of the phase five days after inversion of the LD cycle. Thus a mechanism for photoperiodic entrainment of the daily rhythms of adrenocortical responsiveness to plasma $\mathrm{ACTH}$ (the present study) and plasma corticosteroid concentration (Meier, 1976; Exp. I) is still present in hypophysectomized rats and therefore does not require the presence of the pituitary or a plasma ACTH rhythm. 


\section{EXPERIMENT III}

CIRCADIAN RHYTHMS OF PLASMA CORTICOSTERONE BINDING ACTIVITY AND PLASMA CORTICOSTEROID CONCENTRATION IN MALE RATS 


\section{INTRODUCTION}

The plasma corticosteroid rhythm is caused by a daily rhythm of adrenocortical responsiveness to plasma ACTH (Ottenweller et al., 1978; Dallman et al., 1978; Exp. I). Because corticosteroids inhibit their own synthesis (Black et al., 1961) and binding of ACTH to adrenocortical cell membranes (Latner et al., 1977), plasma binding of corticosteroids may be involved in the rhythm of adrenocortical responsiveness. Protein binding of corticosteroids inhibits their negative feedback on ACTH release by the pituitary (Kawai and Yates, 1966) and may alter corticosteroid synthesis from progesterone by adrenocortical tissue in vitro (Makoff et al., 1964).

Transcortin is a plasma protein which binds corticosteroids with high affinity (Westphal, 1971). This binding influences the activities of corticosteroids both in vivo (Slaunwhite et al., 1962; Kawai and Yates, 1966; Keller et al., 1969) and in vitro (Blecher, 1966, Matsui and Plager, 1966). Because a rhythm of plasma corticosterone binding activity (CBA: An index of transcortin activity) may be important in regulating the plasma corticosteroid rhythm, the present study examined both plasma CBA levels and corticosteroid concertrations in rats at six times of day. 


\section{MATERIALS AND METHODS}

Adult male Charles River (CD strain) albino rats were placed on a 14L:100 regime (onset of light: 0600 ) for two weeks with Purina rat chow and water available ad libitum. At the end of this acclimation period, blood samples were drawn by heart puncture at six times of day under light ether anesthesia. Plasma was separated by centrifugation and stored at $-22^{\circ}$ until assayed.

Plasma corticosteroid concentrations were determined by a modification of the competitive protein binding procedure (see Exp. I). Plasma CBA levels were also measured by a competitive protein binding procedure (Pegg and Keane, 1969). Standard amounts of corticosterone (0-200 ng) in triplicate were added to $0.4 \mathrm{ng}$ tritiated corticosterone $(47.5$ $\mathrm{Ci} / \mathrm{mmol}$ ) and $0.04 \mathrm{ml}$ plasma sample in a final volume of $2.0 \mathrm{ml}$ ethanolsaline solution (2\% ethanol and $0.9 \% \mathrm{NaCl}$ in distilled water). The assay tubes were stirred on a vortex mixer, placed in a $45^{\circ}$ water bath for 5 minutes, and then transferred to a $4^{\circ}$ water bath for 10 minutes. $0.5 \mathrm{ml}$ dextran coated charcoal solution $10.5 \%$ Norit $A$ and $0.05 \%$ Dextran T-70 in distilled water) was added, and the tubes were centrifuged at $2000 \times \mathrm{g}$ for 5 minutes at $4^{\circ}$. A $1.0 \mathrm{ml}$ al iquot of the supernatant was removed from all tubes and added to $10 \mathrm{ml}$ liquid scintillation fluid (0.6\% 2,5-diphenyloxazole and 33\% Triton $x-100$ in spectrograde toluene). The samples were counted to $2 \%$ error with $18 \%$ efficiency. The proportional method was used to estimate plasma CBA levels and affinity constants with correction for non-specific binding (Baulieu and Raynaud, 1970). Interassay variability was $7 \%$.

The data for both plasma CBA levels and corticosteroid 
concentrations were analyzed statistically using Analyses of Variance and orthogonal polynomials (Snedecor and Cochran, 1967). 


\section{RESULTS}

The daily rhythms of plasma CBA levels and corticosteroid concentrations in the rat are presented in Fig. 1. There was a bimodal rhythm of plasma CBA with peak levels at 1000 and $1800(P<0.01)$. The peak concentration of a unimodal rhythm of plasma corticosteroid concentration occurred at $1800(P<0.01)$. The affinity constant for corticosterone binding by rat plasma at $4^{\circ}$ was $3.7 \times 10^{8} \mathrm{~T} / \mathrm{mol}$; this value did not vary significantly during the day. 
Figure 9. Daily rhythms of plasma CBA levels and corticosteroid concentrations in male rats. 14L:10D regime (onset of light: 0600). Closed circles: CBA; open circles: corticosteroid concentrations. Eight animals per group. 


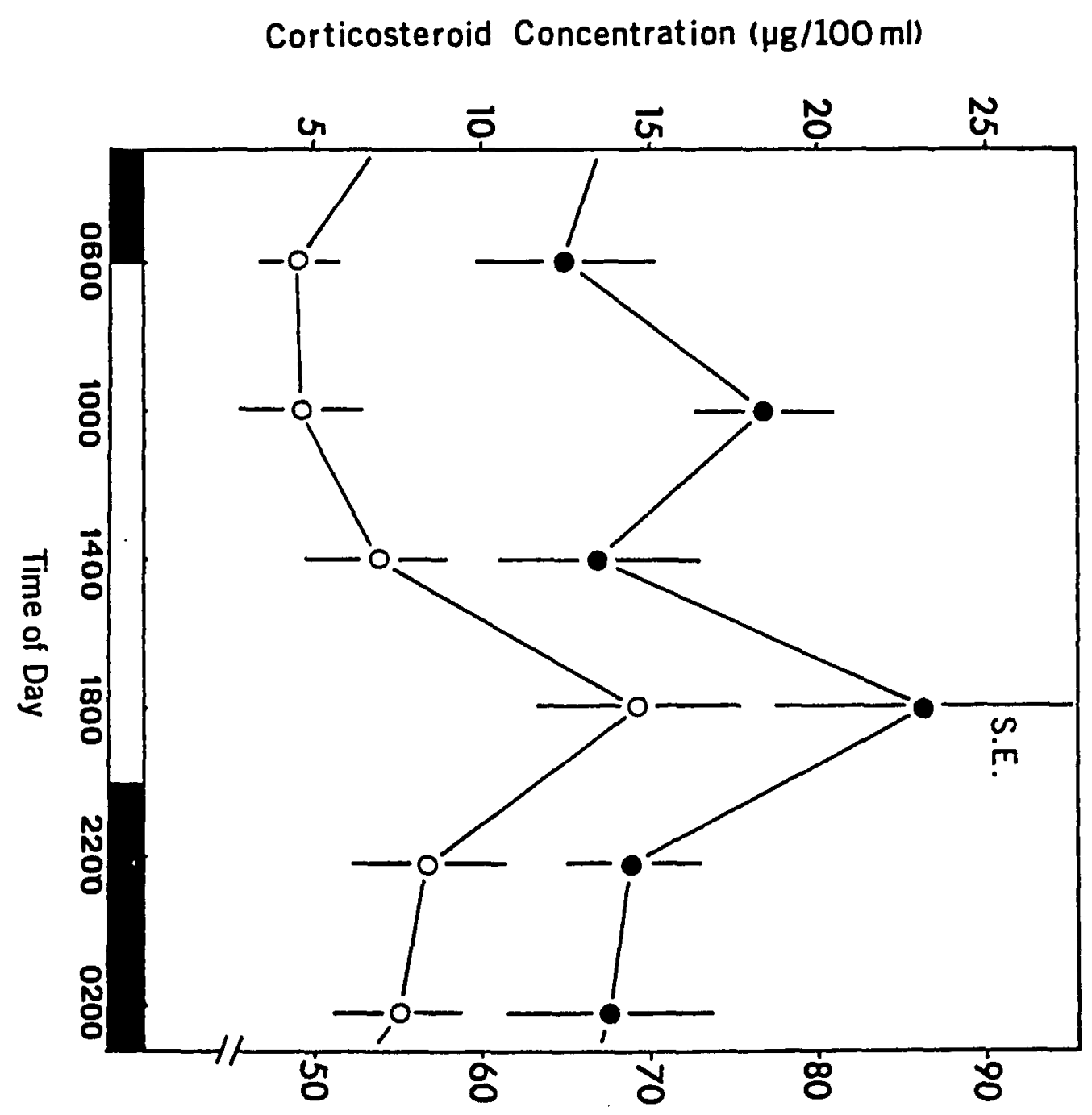

Corticosterone Binding Activity $(\mu \mathrm{g} / 100 \mathrm{ml})$ 


\section{DISCUSSION}

Corticosteroid is present in the plasma in three forms: Unbound, bound to transcortin, or bound to albumin (Slaunwhite and Sandberg, 1959). These three forms exist in an equilibrium that greatly favors the binding of corticosteroid to transcortin (Daughaday, 1957). Changes in plasma CBA levels as well as corticosteroid concentrations might be expected to alter the amount of unbound and bound corticosteroid in the plasma. Unbound plasma corticosteroid is the active moiety in elevating liver glycogen (Slaunwhite et al., 1962), feedback on ACTH release (Kawai and Yates, 1966), inhibiting glucose oxidation in mouse ear strips and rat adipocytes (Matsui and Plager, 1966; Blecher, 1966), and stimulating pancreatic alanine aminotransferase (Keller et al., 1969). However, plasma corticosteroid bound to transcortin stimulates hepatic alanine aminotransferase (Keller et al., 1969) and has a negative ionotropic effect on cardiac tissue (Richardson and Yates, 1964). Because plasma binding affects corticosteroid acitivity, a daily rhythn of plasma CBA may be expected to impose daily variations in corticosteroid activity.

In addition to the plasma CBA rhythm in rats reported in this study, rhythms of plasma CBA have been found in humans (Angeli et al., 1975), chickens (Siegel et al., 1977), white-throated sparrows (Meier et al., 1978), and mice (0ttenweller et al., 1979). The source of these rhythms is not immediately apparent. The half-life of plasma transcortin in humans has been estimated at 4-6 days (Sandberg et al., 1960). Although the half-life of transcortin is not available for rats, a longevity comparable to human transcortin would imply that changes in 
the rate of synthesis and/or degradation cannot completely account for the changes in plasma CBA levels in rats during the day.

Transcortin is found in both plasma and interstitial fluid (Sandberg et al., 1960), and it has been suggested that the plasma CBA rhythm results in part from changes in the distribution of transcortin between the plasma and interstital fluid (Meier et al., 1978). This distribution is presumably related to the permeability of capillaries to transcortin and the rate of Iymphatic return of transcortin to the plasma. A decreased capillary permeability to transcortin results in increased retention of transcortin in the plasma. Under this condition, if lymphatic flow continues to add transcortin to the plasma, plasma CBA levels will increase. Corticosteroids are known to decrease capillary permeability to proteins (Leme and Wilhelm, 1975) and are often elevated at the time of peak locomotor activity (Halbert et al., 1959). It is well known that activity increases the rate of lymphatic return (Guyton, 1976). Therefore increases in locomotor activity which are associated with increased plasma corticosteroid concentration may be expected to increase plasma CBA levels.

Plasma CBA in rats increases near the onset of darkness, wiitch is a time of increased locomotor activity and plasma corticosteroid concentration in these animals. The smaller peak in rat plasma CBA at 1000 may be the result of increased locomotor activity associated with the disturbance of cage cleaning. In man, whose locomotor activity and plasma corticosteroid concentration rise in the morning, plasma CBA is highest at this time (Angeli et al., 1975). In the photosensitive (spring) white-throated sparrow, two peaks of plasma CBA coincide with peaks of locomotor activity and plasma corticosteroid concentration 
(Meier et al., 1978). In chickens, the plasma corticosteroid rhythm anticipates the plasma CBA rhythm by three hours with the peak in plasma CBA occurring near the onset of darkness (Siegel et al., 1977). The daily rhythm of plasma CBA appears to be related in part to locomotor activity, which may affect the rate of iymphatic return of transcortin to the plasma, and in part to plasma corticosteroid concentration, which may affect the capillary permeability and thereby the rate of transcortin movement from the plasma into the interstitial fluid.

Inasmuch as the unbound plasma corticosteroid is the active moiety in the negative feedback of plasma corticosteroid on ACTH secretion (Kawai and Yates, 1966) and the plasma corticosteroid rhythm is not dependent on rhythmic release of ACTH from the pituitary (Meier, 1976; Ottenweller et al., 1978), the question arises as to the role of the plasma CBA rhythm in the regulation of the plasma corticosteroid rhythm. Elevated plasma CBA levals and corticosteroid concentrations in female rats are dependent on estrogen (Sandberg and Slaunwhite, 1959; Gala and Westphal, 1965), and the effect of estrogen on CBA levels appears to precede its effect on corticosteroid concentration (Sandberg et al., 1960). However, the effect of estragen on CBA levels is dependent on the presence of the pituitary (Kawai and Kuzuya, 1972), whereas the plasma corticosteroid rhythm can occur in the absence of the pituitary (Meier, 1976; Exp. I). Also the plasma CBA rhythm lags behind the corticosteroid rhythm in the chicken (Siegel et al., 1977), and in the photorefractory (summer) white-throated sparrow a daily rhythm of plasma CBA occurs in the absence of a plasma corticosteroid rhythm (Meier, unpublished data). Although the daily rhythms of plasma CBA levels and corticosteroid concentrations are closely associated, it appears that 
the plasma CBA rhythm does not directly control the plasma corticosteroid rhythm.

The daily variation of plasma CBA may act in two ways to alter the effect of plasma corticosteroid during the day. Protein binding of steroid hormones is known to alter their clearance from the plasma (Westphal, 1971). The peak of plasma CBA (this study) coincides with the time of the lowest clearance rate of corticosteroid from the plasma (Saba et al., 1963). Therefore the plasma CBA rhythm may be important in regulating the length of time that a surge of corticosteroid secretion results in elevated plasma corticosteroid concentrations. Secondly, protein-bound plasma corticosteroid is limited in its site of action to those tissues with protein-premeable vascular beds (Keller et al., 1969). Therefore changes in the relative concentrations of bound and unbound plasma corticosteroid, caused by changes in plasma CBA levels during the day, may-alter the site of action of plasma corticosteroid during the day. At times of day when plasma CBA is elevated and more corticosteroid is in the bound form, the primary site of action of corticosteroid would be those tissues with protein-permeable vascular beds (liver, heart, etc.). At other times of day when plasma CBA is depressed and the concentration of the unbound form increases, corticosteroid will have greater activity in tissues with protein-impermeable vascular beds (pancreas, brain, etc.).

The timing of the plasma corticosteroid rhythm is important in the regulation of many physiological and behavioral parameters (Meier, 1975). Because either the bound or the unbound plasma corticosteroid may be the physiologically active form, it is important to consider the interrelationship between the daily rhythms of plasma corticosteroid concentration 
and CBA levels to assess the timing of peak physiologically active plasma corticosteroid. 


\section{EXPERIMENT IV}

\section{ADRENAL INNERVATION AND THE DAILY RHYTHM \\ OF PLASMA CORTICOSTEROID CONCENTRATION IN FEMALE RATS}




\section{INTRODUCTION}

After it was concluded that the plasma CBA rhythm does not control directly the plasma corticosteroid rhythm (Exp. III), another approach was taken. The daily rhythm of adrenocortical responsiveness to ACTH (Exp. II) must be controlled by humoral or neural mechanisms. Neural pathways in the spinal cord have been implicated in the control of the plasma corticosteroid rhythm (Allen and Allen, 1975). Exp. IV was designed to distinguish between the possibilities of neural and humoral control by autotransplanting adrenal glands beneath the kidney capsule.

Transplanted adrenal glands resume steroidogenesis after revascularization (Grollman, 1957; Mason et al., 1958). Therefore rats with autotransplanted adrenal glands, which have been revascularized but not reinnervated, present a system by which humoral and neural control of the plasma corticosteroid rhythm might be distinguished. Therefore daily patterns of plasma corticosteroid concentration were measured in intact female rats and in female rats with autotransplanted adrenal glands. Both intact and autotransplanted rats were also subjected to an ether stress test to evaluate the roles of adrenal innervation and ACTH release by the pituitary in this response (see Exp. I). 


\section{MATERIALS AND METHODS}

Adult female Charles River (CD strain) albino rats were placed on a 12L:120 regime (onset of light: 0600 ) with Purina rat chow and tap water available ad libitum. One group of these rats had both adrenal glands removed and autotransplanted beneath the kidney capsules under Nembutal anesthesia (40 mg/kg B.W.), and the other group served as unoperated controls. The rats with autotransplanted adrenal glands were maintained on saline drinking water $(0.9 \% \mathrm{NaCl})$ for one week following surgery and then provided only tap water for two weeks. Survival of these rats on tap water indicated that they were capable of salt retention and therefore had functional adrenal cortices. Blood samples were drawn by tail clip at six times of day from both groups of rats three weeks after surgery on the autotransplanted rats. One week later six rats from each group were subjected to an ether stress test. Blood samples were drawn by tail clip at 1000, the rats were exposed to an ether-saturated atomosphere for 30 seconds, and another blood sample was drawn one hour later (1100).

Plasma was separated from all blood samples by centrifugation and stored at $-22^{\circ}$ until assayed for corticosteroids by a modification of the competitive protein binding procedure (see Exp. I). The results of the rhythm study were analyzed statistically by Analyses of Variance and those of the ether stress test by Student's $\underline{t}$ tests (Snedecor and Cochran, 1967). 


\section{RESULTS}

A daily rhythm of plasma corticosteroid concentration was present in intact rats $(P<0.001)$, but not in rats with autotransplanted adrenal glands ( $F=0.34$ with 5,36 d.f.) (Fig. 1 ). The plasma corticosteroid concentration at 1800 in autotransplanted rats was less than that of intact rats $(P<0.01)$, and the concentration at 0600 was higher in autotransplanted rats but not significantly so. Therefore it appears that trough concentrations (0600) were elevated and peak concentrations (1800) depressed after adrenal autotransplant, so that intermediate concentrations were present throughout the day.

Plasma corticosteroid concentrations were elevated in intact female rats in response to ether stress $(P<0.01$ ) (Fig. 2). However, the ether stress response in autotransplanted rats was suppressed $(P=0.08)$. 
Figure 10. Daily patterns of plasma corticosteroid concentration in intact female rats (intact control) and female rats with autotransplanted adrenal glands. 12L:12D regime (onset of light: 0600). Seven or eight animals per group. 

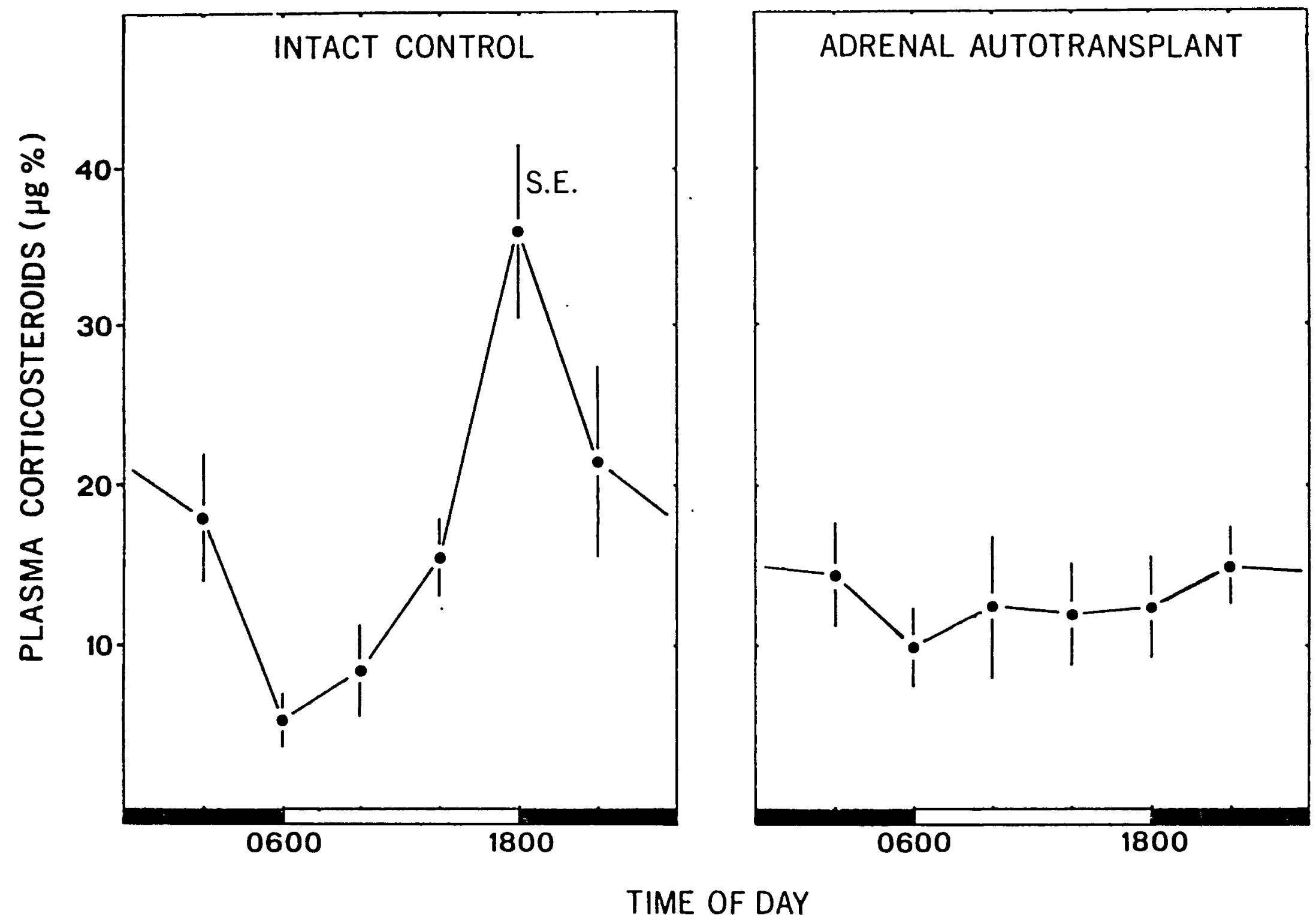
Figure 11. Ether stress response in intact females and females with adrenal autotransplants. Blood was drawn before (Pre) and one hour after (Post) ether exposure at 1000. 12L:12D regime (onset of light: 0600 ). Six to eight animals per group. 
ชิ

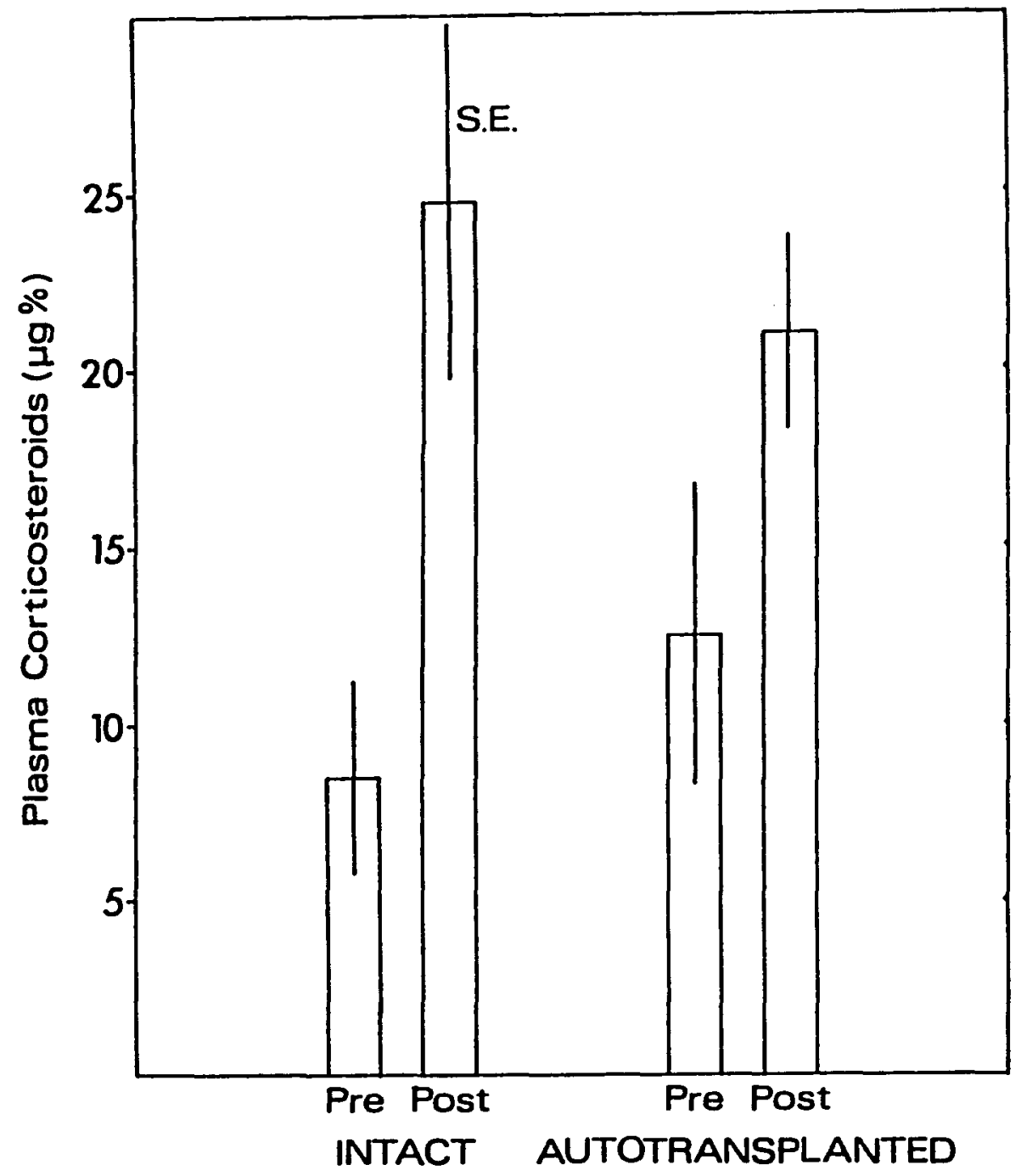




\section{DISCUSSION}

Autotransplanting the adrenal glands of female rats beneath the kidney capsule resulted in loss of the daily rhythm of plasma corticosteroid concentration. Because autotransplanted adrenal glands presumably had been revascularized but not reinnervated, these results indicate that adrenal innervation is necessary for maintainence of the rhythm. This conclusion is supported by results demonstrating that transection of the spinal cord in rats causes loss of the plasma corticosteroid rhythm (Allen and Allen, 1975). In addition, direct neural regulation of the adrenal cortex has been implicated in the compensatory adrenal hypertrophy following contralateral adrenalectomy (Engeland and Dallman, 1975).

A daily rhythm of adrenocortical responsiveness to plasma ACTH is abolished by $p$-chlorophenylalanine (PCPA) in spite of the persistence of a plasma ACTH rhythm (Dallman et al., 1978). Other serotonin antagonists abolish the plasma corticosteroid rhythm (Krieger and Rizzo, 1969), but the effect of PCPA on the rhythm is not as clear (Scapagnini et al., 1971). Inasmuch as adrenalectomy does not abolish the plasma ACTH rhythm in rats (Cheifetz et al., 1968), it is probable that a daily rhythm of plasma ACTH was present in adrenal autotransplanted rats. If such is the case, the results of the present study confirm previous results which indicated that a plasma ACTH rhythm does not necessarily cause a plasma corticosteroid rhythm (0ttenweller et al., 1978).

Ether stress elevates plasma ACTH concentrations in adrenal autotransplanted rats in the same manner as intact rats (Allen et al., 1975). Inasmuch as the ether stress response was suppresssed in adrenal 
autotransplanted rats, some role of adrenal innervation in the ether stress response may be indicated. The results of the present study suggest that adrenal innervation stimulates adrenocortical responsiveness to ACTH released by ether stress. Therefore both adrenal innervation and ACTH release are required for a maximal ether stress response. Much work has been done concerning hypothalamic influences on the plasma corticosteroid rhythm with the assumption that the hypothalamus exerts its influence on plasma corticosteroid concentration by regulating pituitary secretion of ACTH (Halasz et al., 1967; Krieger, 1977). However, hypothalamic stimulation is capable of increasing corticosteroid secretion by the adrenal gland in the absence of the pituitary (Kovach et al., 1970). Thus hypothalamic control of the plasma corticosteroid rhythm may be mediated by a neural pathway from the hypothalamus to the adrenal gland which includes fibers in the spinal cord (Allen and Allen, 1975). Neural signals to the adrenal cortex may set a rhythm of adrenocortical responsiveness to plasma ACTH (Ottenweller et al., 1978). This rhythm of responsiveness is entrained by the photoperiod and may have a major role in setting the phase of the plasma corticosteroid rhythm. 


\section{EXPERIMENT $V$}

DISRUPTION OF ADRENAL INNERVATION ABOLISHES THE PLASMA CORTICOSTEROID RHYTHM AND THE DAILY VARIATION OF ADRENOCORTICAL RESPONSIVENESS TO ACTH IN MALE RATS 


\section{INTRODUCTION}

The daily rhythm of plasma corticosteroid concentration is caused by a daily rhythm of adrenocortical responsiveness to plasma adrenocorticotropin (ACTH) (Ottenweller et al., 1978; Dallman et al., 1978) and depends on intact innervation of the adrenal gland (Allen and Allen, 1975; Exp. IV). Because of uncertainty as to the degree of regeneration of the autotransplanted adrenal glands in Exp. IV, another method was used to disrupt adrenal innervation. Spinal cord transection was used to examine the role of adrenal innervation in the plasma corticosteroid rhythm, the daily variation of adrenocortical responsiveness to ACTH, and the ether stress response.

The nerve supply of the adrenal gland has been implicated in the control of adrenocortical function (Kovach et al., 1970; Allen and Allen, 1975; Engeland and Dallman, 1975). Nerve fibers innervating the adrenal cortex exit the spinal cord at the levels of the ninth, tenth, and eleventh thoracic vertebrae (T-9 through T-11) (Kiss, 1951). Spinal cord transection above this area at the T-5 level, but not at the leve $\mathrm{T}$ of the first lumbar vertebrae $(L-1)$, abolishes the plasma corticosteroid rhythm in rats (Allen and $A 7 l e n, 1975)$. In the present study, an attempt was made to confirm these results by transecting the spinal cords of male rats at the $T-7$ or $L-1$ levels and measuring the plasma corticosteroid concentration at six times of day.

A daily rhythm of adrenocortical responsiveness to ACTH is present in vivo (Haus, 1964; Sadow et al., 1974; Singh et al., 1975; Yasuda et al., 1976; Dallman et al., 1978) and in vitro (Ungar and Halberg, 1962; Ungar, 1963; Haus, 1964). The present study examined the daily 
variation in adrenocortical responsiveness to exogenous $A C T H$ in intact and spinal cord transected ( $T-7$ and $L-1)$ rats in an attempt to demonstrate neural control of this rhythm.

The elevation of plasma corticosteroid concentration in response to ether stress was examined in intact and spinal cord transected rats to evaluate the roles of adrenal innervation and ACTH release by the pituitary in the ether stress response (see Exps. I and IV). 


\section{MATERIALS AND METHODS}

Adult male Charles River (CD strain) albino rats were placed on a 12L:12D regime (onset of light: 0600 ) with Purina rat chow and water available ad libitum. The rats were divided into three groups. The spinal cords of one group were transected at the T-7 level under Nembutal anesthesia (40 mg/kg B.W.), and those of a second group at the L-l level. The third group of rats served as unoperated controls. Because nerve fibers that innervate the adrenal cortex exit the spinal cord at levels T-9 through T-11 (Kiss, 195T), neural innervation of the adrenal cortex was disrupted in $T-7$ transected rats but not in L-1 transected rats which served as operated controls. The success of cord transection was judged by loss of motor and sensory function in the hind limbs of the rats.

One week after surgery, blood samples were drawn by tail clip at six times of day (every four hours) from all three troups of rats to examine the daily patterns of corticosteroid concentration. One week later, the daily variation in adrenocortical responsiveness to ACTH injections was examined in all three groups. Half the rats of each group were injected intraperitoneally at 0600 with either 2.0 IU ACTH (in 0.5 $\mathrm{ml} 0.9 \% \mathrm{NaCl}$ ) or $0.5 \mathrm{ml} 0.9 \% \mathrm{NaCl}$. The other half received $\mathrm{ACTH}$ or $\mathrm{NaCl}$ at 1800. Blood samples were drawn by tail clip one hour after innections. One week after this study, six rats from each group were subjected to an ether stress test. Blood samples were drawn by tail clip at 1000, the rats were exposed to an ether-saturated atmosphere for 30 seconds, and another blood sample was drawn one hour later (1100). Plasma was separated from all blood samples by centrifugation and 
stored at $-22^{\circ}$ until assayed for corticosteroids by a modification of the competitive protein binding procedure (see Exp. I). The data were analyzed statistically using Analyses of Variance and Duncan Multiple Range tests (Snedecor and Cochran, 1967). 
RESULTS

Similar plasma corticosteroid rhythms were present in intact control and $L-1$ transected rats $(P<0.05)$, but not in $T-7$ transected rats (Fig. 1). Although a rhythm was present in $L-1$ transected rats and absent in T-7 transected rats, the mean concentration during the day (average of concentrations at the six sampling times) was not significantly different between these groups (L-1: 7.7 ug\%; T-7: 8.3 ug\%); indicating similar capacities to maintain plasma corticosteroid concentration in these two groups. The lack of a rhythm in T-7 transected rats apparently resulted from decreased peak concentrations and increased trough concentration during the day as compared with L-1 transected rats.

ACTH injections resulted in significantly greater plasma corticosteroid concentrations than saline injections $(P<0.05)$ in all groups except at 0600 in intact and T-7 transected rats, indicating a specific corticosteroid response to ACTH (Fig. 2). Saline injections at 1800 resulted in significantly greater plasma corticosteroid concentrations than saline injections at $0600(P<0.05)$ in intact rats but not in either group of transected rats. However, ACTH injections at 1800 resulted in significantly greater plasma corticosteroid concentration than ACTH injections at $0600(P<0.05)$ in both intact and $L-1$ transected rats but not in T-7 transected rats. Although the daily variation of plasma corticosteroid concentration after ACTH injection in intact rats may be due to a variation in response to injection alone (saline injections), such is not the case in $L-1$ transected rats.

Ether stress at 1000 elevated plasma corticosteroid concentrations 
in intact and $L-1$ transected rats $(P<0.05)$, but the ether stress response was suppressed in T-7 transected rats (Fig. 3). Post-stress concentrations were lower in $\mathrm{T}-7$ transected rats than in either intact or $L-1$ transected rats $(P<0.05)$, indicating that ether stress had less effect in T-7 transected rats.

In the study of ACTH responsiveness, plasma corticosteroid concentrations after saline injections were greater in $L-1$ transected rats than in intact control $(P<0.01)$. The enhanced response to the stress of control injections indicates differences in adrenocortical function between these groups and places doubt on the "control" nature of L-1 transection. 
Figure 12. The effect of spinal cord transection on the plasma corticosteroid rhythm. Blood was drawn at six times of day from intact male rats and male rats with spinal cords transected at the $T-7$ or $L-1$ level. 12L:12D regime (onset of light: 0600). Five to eight animals per group. 


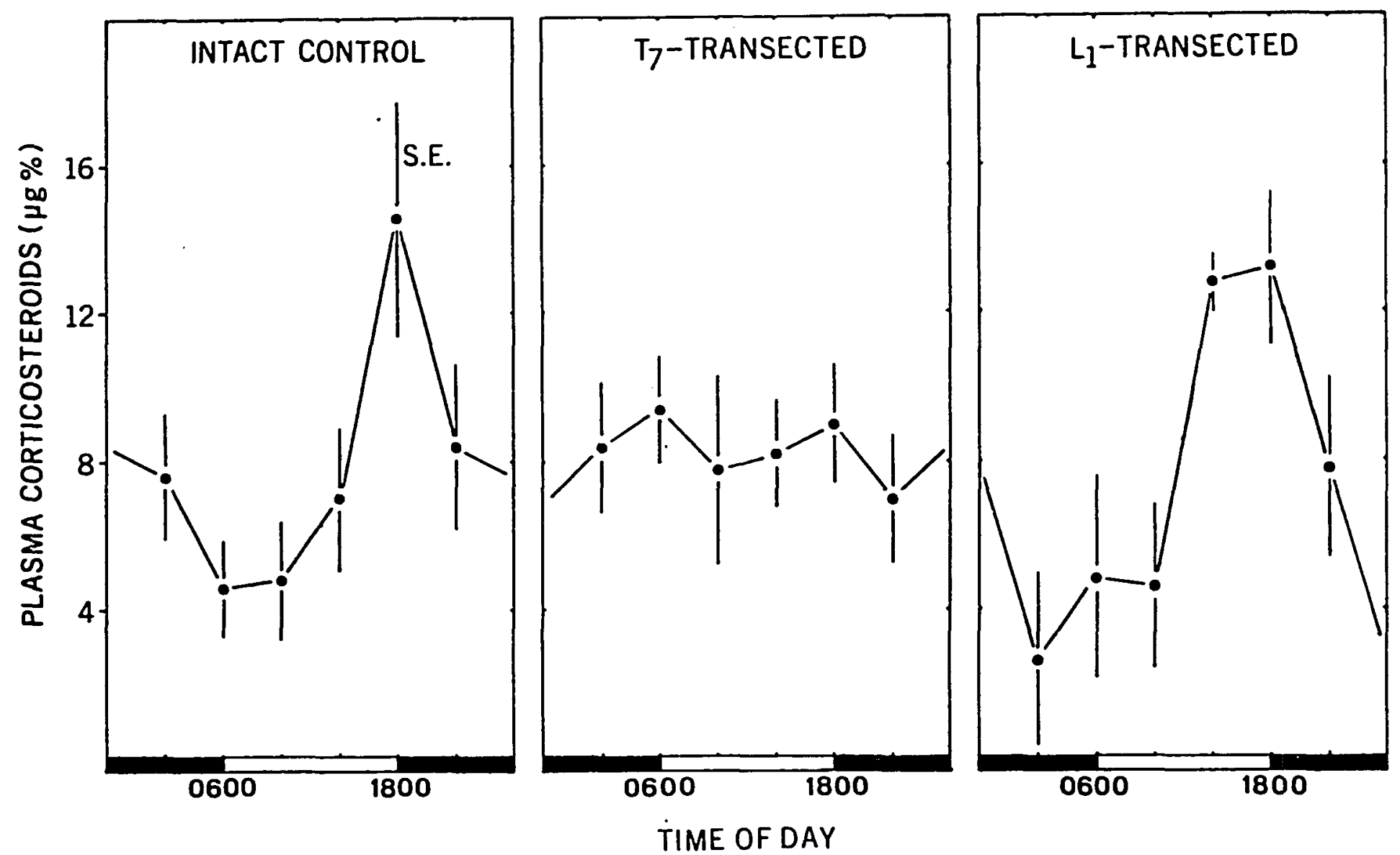


Figure 13. Effect of spinal cord transection on daily variations in adrenocortical responsiveness to ACTH. Blood was drawn one hour after injections (i.p.) of ACTH or $\mathrm{NaCl}$ at 0600 (AM) or 1800 (PM) in intact, T-7 transected, and L-T transected male rats. 12L:12D regime (onset of light: 0600). Five to eight animals per group. 


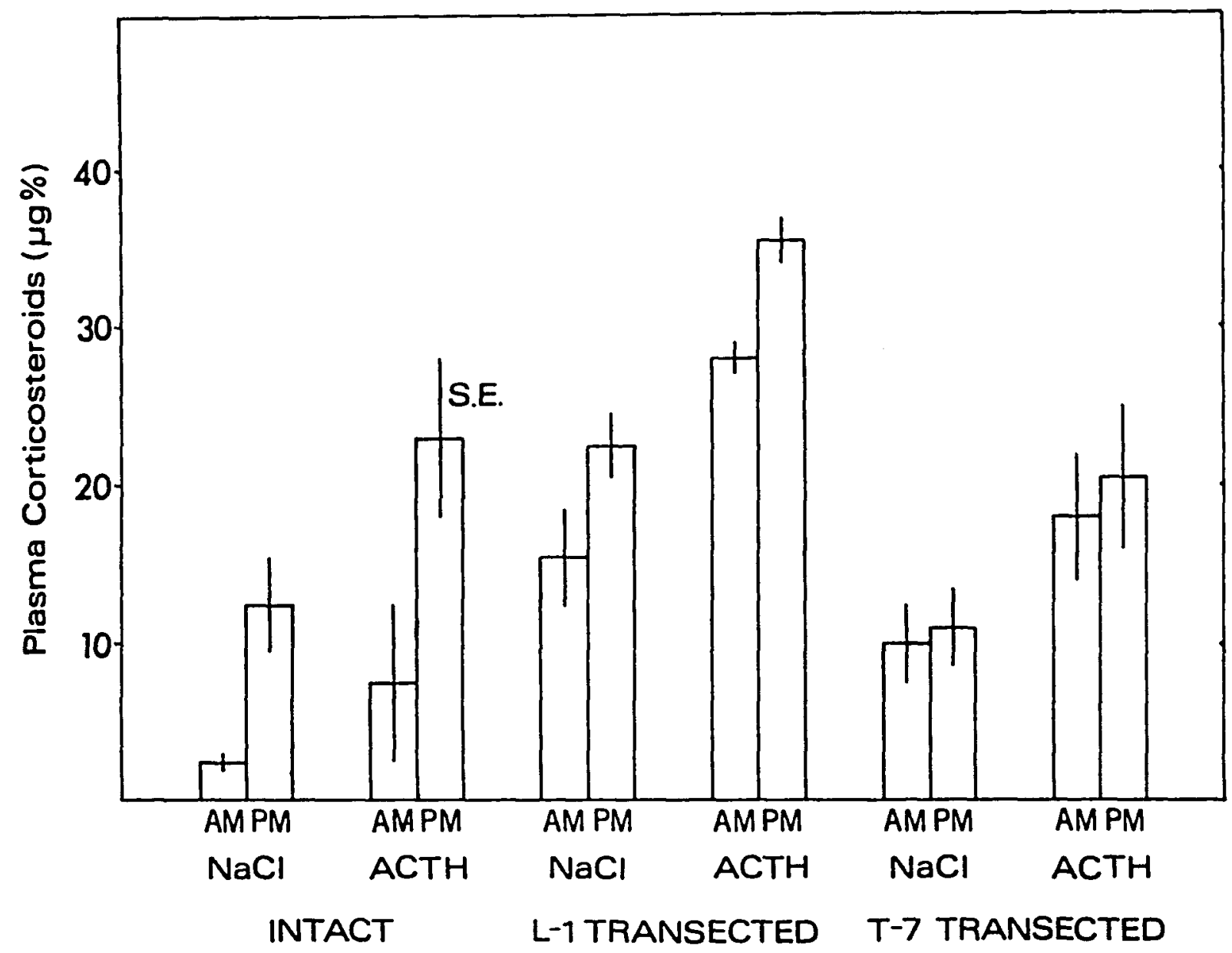


Figure 14. Ether stress response in intact, T-7 transected, and L-1 transected male rats. Blood was drawn before (Pre) and one hour after (Post) ether exposure at 1000. 12L:120 regime (onset of light: 0600). Six to eight animals per group. 


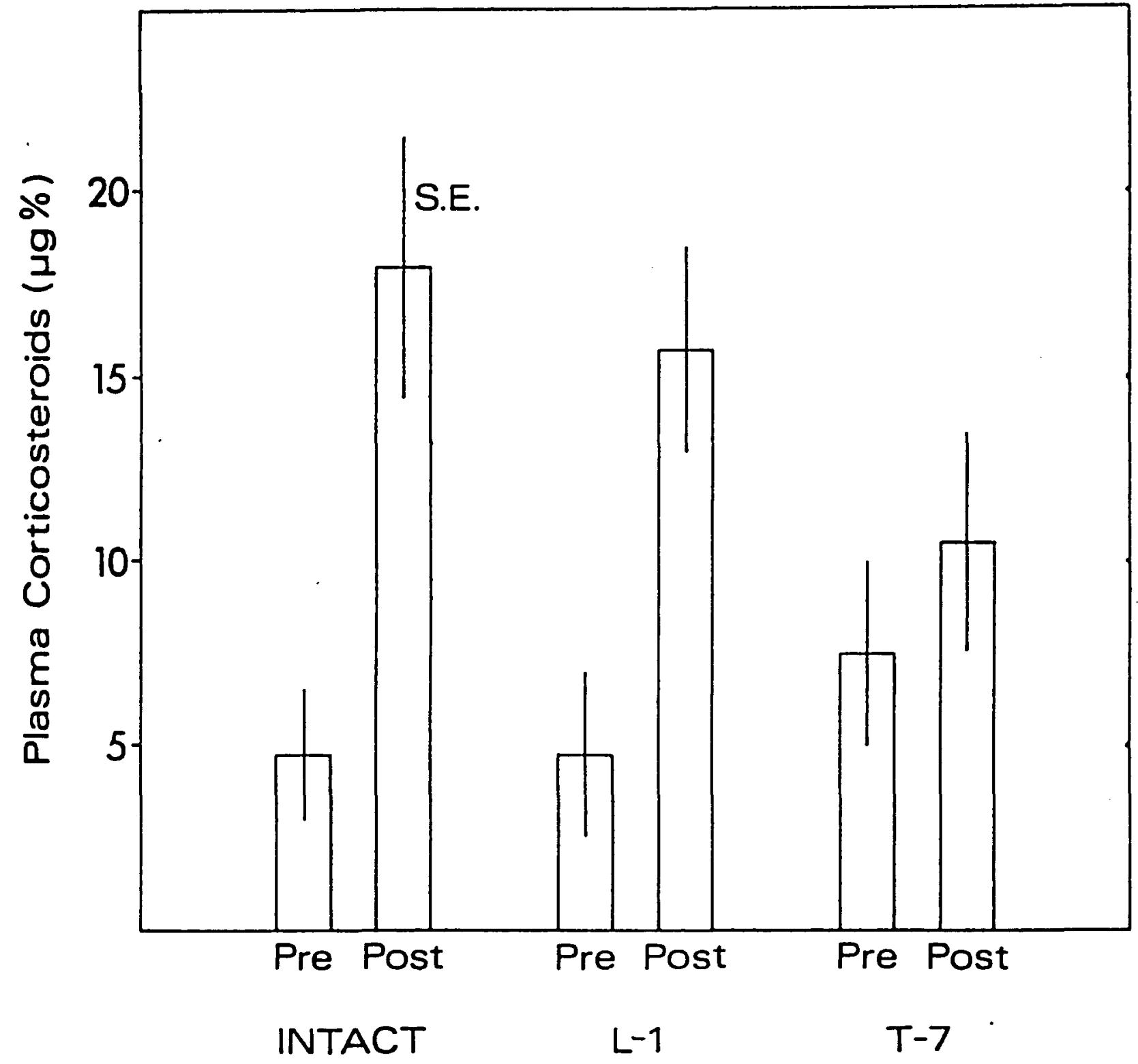




\section{DISCUSSION}

The daily rhythm of plasma corticosteroid concentration depends on a daily rhythm of adrenocortical responsiveness to ACTH which is controlled by innervation of the adrenal gland (0ttenweller et al., 1978). Spinal cord transection which disrupted adrenal innervation abolished the plasma corticosteroid rhythm in the present study, confirming earlier results which indicated that adrenal innervation is essential for the rhythm (Allen and Allen, 1975; Ottenweller et al., 1978). Adrenal innervation has been implicated in the elevation of plasma corticosteroid concentration following hypothalamic stimulation (Kovach et al., 1970) and in compensatory adrenal hypertrophy following contralateral adrenalectomy (Engeland and Dallman, 1975).

Plasma corticosteroid concentrations following ACTH injections are greater at the offset of light than at the onset of light in hypophysectomized rats (Ottenweller et al., 1978), and the present study indicates that the same is true in intact and $L-1$ transected rats. Although this variation of responsiveness in intact rats might have been due to the effect of injection alone, this was not the case in $L-T$ transected rats in which the response to saline injection was not significantly different at the two times of day. Plasma corticosteroid concentrations in T-7 transected rats after either saline or ACTH injections did not vary significantly between the onset and offset of light, indicating that disruption of adrenal innervation which abolishes the plasma corticosteroid rhythm also abolishes the daily variation of adrenocortical responsiveness to ACTH. Therefore the present study supports the previously presented conclusion (Ottenweller et al., 1978), that the 
plasma corticosteroid rhythm is the result of a rhythm of adrenocortical responsiveness to plasma $A C T H$ which depends on intact adrenal innervation.

Disruption of adrenal innervation by spinal cord transection suppressed the ether stress response, indicating that adrenal innervation is an important factor in the ether stress response. Adrenal innervation may increase adrenocortical responsiveness to ACTH released by the pituitary during ether stress. Therefore both adrenal innervation and ACTH release from the pituitary are required for maximal elevation of plasma corticosteroid concentration in response to ether stress.

The plasma corticosteroid rhythm is not dependent on rhythmic release of ACTH by the pituitary (Srivastava and Meier, 1972; Meier, 1976; Exp. I), but rather on a daily rhythm of adrenocortical responsiveness to plasma ACTH (Ottenweller et al., 1978; the present study). The hypothalamus has often been implicated in the regulation of adrenalcortical function (for review see Naumenko, 1973). It has been assumed that hypothalamic regulation of the adrenal $\mathrm{gland}$ is mediated by control of ACTH release by the pituitary (Krieger, 1977). However, there is a direct neural pathway between the hypothalamus and the adrenal cortex (Halasz and Szentagothai, 1959; Kovach et al., 1970; Engeland and Dallman, 1975): Therefore neural signals may travel from a circadian oscillator in the hypothalamus (Kawamura and Ibuka, 1978) to the adrenal gland where they result in a daily rhythm of adrenocortical responsiveness to plasma ACTH (Ottenweller et al., 1978; the present study) which sets the phase of the plasma corticosteroid rhythm. This neural pathway, in conjunction with release of ACTH from the pituitary, may also be involved in the ether stress response. 
GENERAL DISCUSSION

The daily rhythm of plasma corticosteroid concentration controls many other physiological rhythms (review Meier, 1975), as might be expected from the ubiquitous influence of corticosteroids on vertebrate cells (Bentley, 1976). Because the plasma corticosteroid rhythm is entrained by environmental rhythms (Crichlow et al., 1973; Johnson and Levine, 1973; Krieger, 1974; Gibbs, 1976; Morimoto et al., 1977), it coordinates physiological rhythms with environmental rhythms and better adapts an animal to its environment.

Because the plasma ACTH rhythm persists in adrenalectomized rats (Cheifetz et al., 1968) and the CRH rhythm persists in hypophysectomized rats (Takebe et al., 1972), it has been assumed that the CRH rhythm produces a plasma ACTH rhythm which in turn drives the plasma corticosteroid rhythm (Krieger, 1977). Presumably, a hypothalamic circadian oscillator which is neurally connected to the CRH-containing neurons of the medial basal hypothalamus (Moore and Eichler, 1972; Kawamura and Ibuka, 1978) controls the CRH rhythm. This model was challenged by reports of plasma corticosteroid rhythms in hypophysectomized fish and rats which lacked a plasma ACTH rhythm (Srivastava and Meier, 1972; Meier, 1976).

The plasma corticosteroid rhythm in hypophysectomized rats responds to inversion of the LD cycle and to anticholinergic drugs in a manner similar to intact rats (Meier, 1976; Exp. I), indicating that the pituitary (or ACTH rhythm) is not part of the mechanism controlling the phase of the plasma corticosteroid rhythm. A rhythm of adrenocrotical responsiveness to plasma ACTH is essential for the plasma corticosteroid rhythm in both hypophysectomized and intact rats (Ottenweller et al., 
1978; Dallman et al., 1978). This rhythm of responsiveness depends on intact adrenal innervation (Exp. V), indicating that neural input to the adrenal gland alters adrenocortical responsiveness to plasma ACTH. during the day.

The probable source of the neural impulses which alter adrenocortical responsiveness to ACTH is the hypothalamus. Hypothalamic lesions abolish the plasma corticosteroid rhythm (Slusher, 1964; Halasz et al., 1967; Palka et al., 1969; Moore and Eichler, 1972; Bouille et al., 1975; Bellinger et al., 1976), whereas higher centers are not essential for the rhythm (Galicich et al., 1965; Wilson and Critchlow, 1973; Seggie et al., 1974; Wilson and Critchlow, 1974). In addition, hypothalamic stimulation of hypophysectomized dogs alters corticosteroid secretion (Kovach et al., 1970), indicating that hypothalamic lesions which abolish the plasma corticosteroid rhythm may act independent of their effect on plasma ACTH.

In light of the research on the plasma corticosteroid rhythm, it is likely that a circadian oscillator in the hypothalamus is coupled to the adrenal gland by a neural pathway which alters adrenocortical responsiveness to plasma ACTH during the day. Such a pathway is represented by the structures diagrammed in Fig. 1. The pathway is divided into stimulatory and inhibitory parts because intermediate plasma corticosteroid concentrations during the day after disruption of adrenal innervation (Exps. IV and $V$ ) indicate active stimulatory and inhibitory phases in the control of plasma corticosteroid concentrations during the day. The following discussion presents the research supporting this model 
Figure 15. Diagram of stimulatory and inhibitory pathways which are thought to regulate the plasma corticosteroid rhythm. 


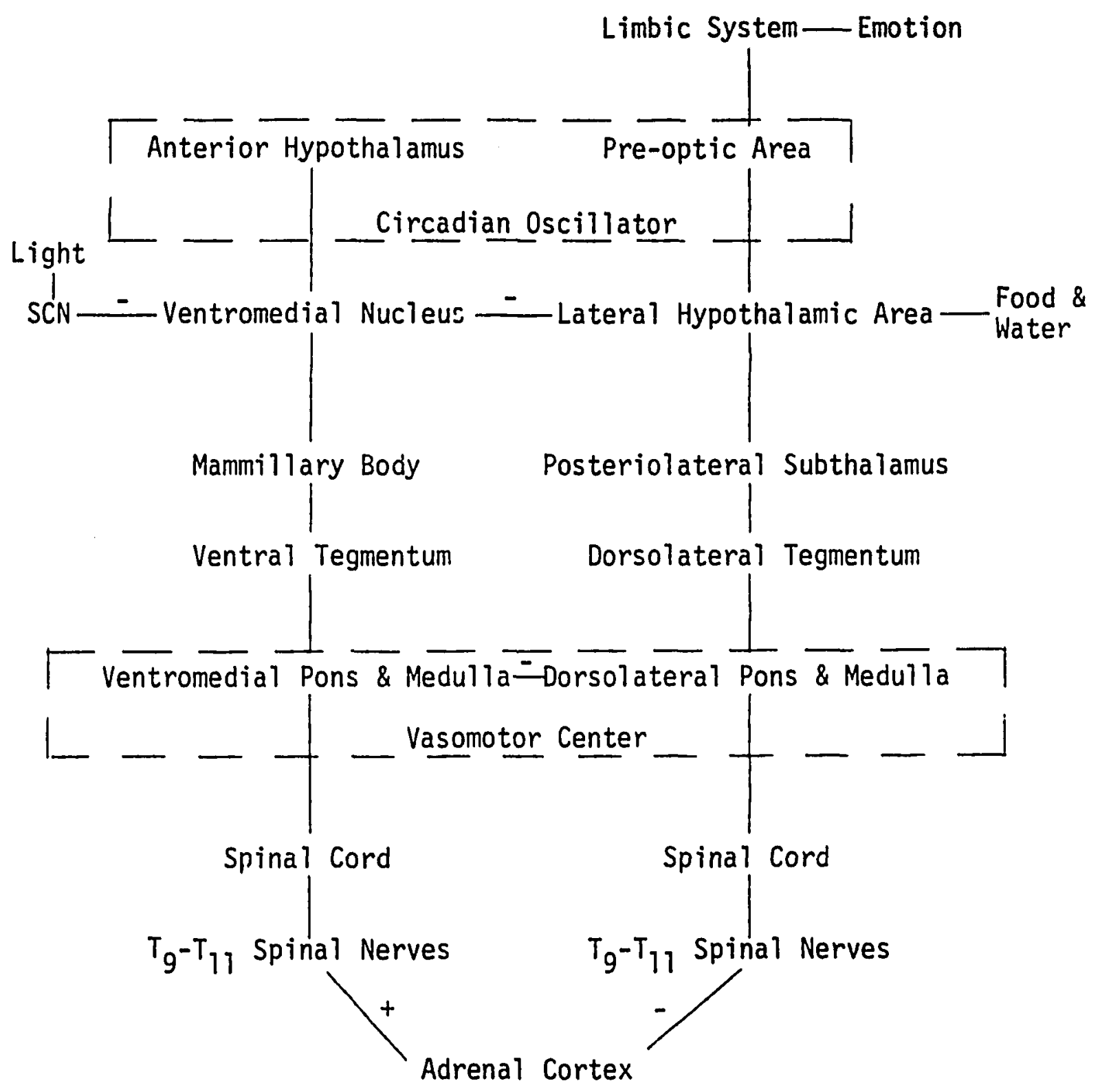


Circadian rhythms of single unit neural activity are present in the ventromedial nucleus (VMN) and the lateral hypothalamic area (LHA). Both these rhythms and the plasma corticosteroid rhythm are abolished by frontal deafferentation of the hypothalamus (Bouille et al., 1975; Koizumi and Nishino, 1976; Phelps et al., 1978), indicating that a circadian oscillator which controls these rhythms must be anterior to the VMN and LHA. Anterior connections with the hypothalamus project from the suprachiasmatic nucleus, the limbic system (hippocampus, amygdala, and septum), and the raphe nucleus. Although the SCN is necessary for photoperiodic entrainment (Moore and Eichler, 1972; Stephan and Zucker, 1972), the plasma corticosteroid rhythm and therefore the circadian oscillator are entrained by restricted feeding regimes in SCN-lesioned rats (Krieger et al., 1977). In spite of this, some researchers still think that the circadian oscillator is located in the SCN (Kawamura and Ibuka, 1978). Extensive lesions of the limbic system (Galicich et al., 1965; Bouille and Bayle, 1973; Seggie et al., 1974; Wilson and Critchlow, 1974) and the raphe nucleus (Balestrery and Moberg, 1976) do not abolish the plasma corticosteroid rhythm, indicating that these structures are also not essential parts of the circadian oscillator.

Frontal deafferentation of the hypothalamus usually involves sectioning nerves at the level of the optic chiasma, which destroys the connections of a small area of the anterior hypothalamus and the preoptic area with the remainder of the hypothalamus (Szentagothai et al., 1965). Lesions in the anterior hypothalamus abolish the plasma corticosteroid rhythm (Slusher, 1964). Atropine implants in the anterior hypothalamus decrease plasma corticosteroid concentration (Hedge and Smelik, 1968), indicating that activity of cholinergic neurons in this area 
elevates plasma corticosteroid concentration. Serotonin (5-HT), Norephinephrine (NE), and dopamine (DA) rhythms are present in the anterior hypothalamus; their activities may also control plasma corticosteroid concentrations (Dixit and Buckely, 1967; Krieger and Rizzo, 1969; Naumenko, 1973; Scapagnini et al., 1971; Simon and George, 1975). Because adrenal blood flow affects corticosteroid secretion (Urquhart, 1965; Kovach et al., 1970; L'Age et al., 1970), it is important to note that a small area of the anterior hypothalamus is important in vasomotor control (Folkow et al., 1959).

A circadian rhythm of multiple unit neural activity is present in the pre-optic area, and this rhythm may be related to the plasma corticosteroid rhythm (Johnson et al., 1971). In contrast to the anterior hypothalamus, electrical and chemical stimulation of the pre-optic area decreases plasma corticosteroid concentration (Suzuki et all., 1960; Slusher and Hyde, 1966;. Endroczi et al., 1963). The circadian oscillator appears to be composed of a stimulatory area in the anterior hypothalamus and an inhibitory area in the pre-optic area. In the rat, anterior hypothalamic activity dominates near the onset of darkness and through the dark period, whereas pre-optic activity dominates near the onset of light and through the light period.

Neural pathways from the circadian oscillators in the anterior hypothalamus and pre-optic area project posteriorly with stimulatory pathways being more medial and ventral (VMN) than inhibitory pathways (LHA). Many experiments have indicated the essential nature of the VMN in regulating the plasma corticosteroid concentration (Brodish, 1963; Slusher, 1964; Halasz et al., 1967; Bohus et al., 1968; Kovach et al., 1970; Bellinger et al., 1976). The VMN is the corticophysiotropic area 
with CRH-containing neurons projecting into the median eminence, and so researchers have assumed that the VMN alters plasma corticosteroid concentration by altering the release of CRH and ACTH (Krieger, 1977). However, both electrical and chemical stimulation of the VMN can alter plasma corticosteroid concentration without release of ACTH from the pituitary (Kovach et al., 1970; Krieger and Krieger, 1970).

Circadian rhythms of both single and multiple unit neural activity are present in the VMN and are in phase with the plasma corticosteroid rhythm (Koizumi and Nishino, 1976; Bouille and Bayle, 1976). Electrical and chemical stimulation of the VMN increases plasma corticosteroid concentration (Endroczi et al., 1963; Krieger and Krieger, 1970), and electrical stimulation has this effect in the absence of the pituitary (Kovach et al., 1970). Lesions of the VMN abolish the plasma corticosteroid rhythm (Bellinger et al., 1976).

The circadian rhythm of single unit neural activity in the LHA is $180^{\circ}$ out of phase with the rhythm in the UNW, and the activities of these centers are mutually inhibitory. Chemical and electrical stimulation of the LHA decreases plasma corticosteroid concentration (Endroczi and Lissak, 1963; Endroczi et al., 1963), and electrical stimulation of the LHA has this effect in hypophysectomized animals (Kovach et al., 1970). Because the rhythms of neural activity in the LHA responds to plasma glucose and osmolarity in a phase-specific manner (Schmitt, 1973), the LHA may be the point at which feeding and watering regimes act to entrain the circadian oscillator and plasma corticosteroid rhythm.

Neural connections between the hypothalamus and the vasomotor center include again ventromedial stimulatory and dorsolateral inhibitory 
pathways. Electrical and chemical stimulation of the mammillary body and ventral tegmentum increase plasma corticosteroid concentration, whereas stimulation of the posterior subthalamus and dorsal tegmentum decrease it (Endroczi and Lissak, 1963; Endroczi et al., 1963). Electrical stimulation of the mammillary body and ventral tegmentum also has a stimulatory effect in hypophysectomized animals (Kovach et al., 1970).

The vasomotor centers in the posterior pontine and anterior medullary areas are included in the pathway because adrenal blood flow alters corticosteroid secretion (Bush, 1953; Urquhart, 1965; Kovach et al., 1970; L'Age et al., 1970). In particular, electrical stimulation of the hypothalamus and lower brain stem increases adrenal blood flow and corticosteroid secretion in a similar manner in hypophysectomized animals (Kovach et al., 1970). In addition, many brain centers which control plasma corticosteroid concentration (see above) are involved in vasomotor control (Folkow et al., 1959; Manning and Peiss, 1960; Mountcastle, 1974). The dorsolateral part of the vasomotor center is vasoconstrictive, whereas the ventromedial part is vasodilatory; these two areas are mutually inhibitory (Mountcastle, 1974).

The intermediolateral cell column of the spinal cord contains vasomotor fibers which exit the cord between the first thoracic and third lumbar vertebrae. The greater splanchnic nerve consists of fibers originating between the fifth and tenth thoracic vertebrae and is the main source of nerve fibers innervating the adrenal cortex (Kiss, 1951). Splanchnic nerve stimulation increases corticosteroid secretion by the adrenal cortex (Voight, 1944), and section of the nerve decreases adrenal blood flow and corticosteroid secretion (Bush, 1953). Because spinal 
cord transection at the $T-7$ level abolishes the daily rhythms of plasma corticosteroid concentration and adrenocortical responsiveness to plasma ACTH (Exp. V), the greater splanchnic nerve may conduct impulses that alter adrenal blood flow and thus adrenocortical responsiveness to plasma ACTH.

Although the pathway outlined above is supported by anatomical evidence and the results of electrical and chemical stimulation studies, the functional integrity of such a pathway would be its strongest support. Light on the retina or electrical stimulation of the optic nerve excite certain groups of neurons in the suprachiasmatic nucleus which inhibit the activity of cervical sympathetic nerves by a pathway which includes the VMN and LHA (Koizumi and Nishino, 1976; Nishino et al., 1976). In addition, rhythms of neurotransmitter concentration in the anterior hypothalamus are in phase with similar rhythms in the cervical spinal cord (Reis et al., 1968; Reis et al., 1969; Simon and George, 1975). These experiments suggest that the neural pathways proposed for control of the plasma corticosteroid rhythm function rhythmically as stimulatory or inhibitory units.

It is important to note that this model only includes evidence of a neural pathway between a circadian oscillator in the hypothalamus and the adrenal gland to demonstrate the possibility of such a pathway that could regulate the plasma corticosteroid rhythm. A discussion of all the factors involved in the regulation of the plasma corticosteroid rhythm is beyond the scope of the discussion.

In sumary, neither the plasma ACTH rhythm nor the pituitary is an essential part of the mechanism by which the phase of the plasma corticosteroid rhythm is set. Rather, a putative circadian oscillator in 
anterior hypothalamic area sets the phase of the plasma corticosteroid rhythm by direct neural connections between this oscillator and the adrenal gland. Both stimulatory and inhibitory neural pathways are involved in producing the plasma corticosteroid rhythm, and they pass through the diencephalon, telencephalon, and the spinal cord. A daily rhythm of neural activity in the greater splanchnic nerve produces a rhythm of adrenocortical responsiveness to plasma ACTH which sets the phase of the plasma corticosteroid rhythm. 


\section{LITERATURE CITED}

Ader, R. 1969. Early experiences accelerate maturation of the 24-hour adrenocortical rhythm. Science 163:1225-1226.

Allen, C. and J.W. Kendall. 1969. Maturation of the circadian rhythm of plasma corticosterone in the rat. Endocrinology 80:926-930.

Allen, C.F. and J.P. Allen. 1975. Spinal cord transection blocks circadian rhythmicity of corticosterone in the rat. Fed. Proc. $34: 424$.

Allen, C.F., J.P. Allen, and M.A. Greer. 1975. Absence of nycterohemeral variation in stress-induced ACTH secretion in the rat. Aviat. Sp. Eng. 46:296-299.

Angeli, A., R. Frajria, F. Agrimonti, L. Ricchiardi, G. Boccuzzi, and F. Ceresa. 1975. Circadian variations of cortisol binding capacity by transcortin in normal subjects. Chronobiologia suppl. $1: 4$.

Andrews, R.V. and G.E. Folk. 1963. Respiratory circadian periodicity in cultured hamster adrenals. Fed. Proc. 22:382.

Balestrery, F.G. and G.P. Moberg. 1976. Effect of midbrain raphe nuclei lesions on the circadian rhythm of plasma corticosterone in the rat. Brain Res. 118:503-508.

Baulieu, E.E. and J.P. Raynaud. 1970. A "proportion graph" method for measuring binding systems. Europ. J. Biochem. 13:293-304.

Bellinger, L.L., L.L. Bernardis, and V.E. Mendel. 1976. Effect of ventromedial and dorsomedial hypothalamic lesions on circadian corticosterone rhythms. Neuroendocrinology 22:216-225.

Bentley, P.J. 1976. "Comparative vertebrate endocrinology." Cambridge 
University Press, Cambridge. 415 pp.

Black, W.C., R.S. Crampton, A.S. Verdesca, R.I. Nedeljkovic, and J.G. Hilton. 1961. Inhibitory effect of hydrocortisone and analogues on adrenocortical secretion in dogs. Am. J. Physiol. 201:1057-1060. Blecher, M. 1966. Serum protein-steroid hormone interactions. Effects of glucocorticoids on glucose metabolism in rat adipose isotated cells, and the influence of human plasma corticosteroid binding protein. Endocrinology 79:541-546.

Bliss, E.L., A.A. Sandberg, D.H. Nelson, and K. Eik-Nes. 1953. The normal levels of 17-hydrocorticosteroids in the peripheral blood of man. J. Clin. Invest. 32:818-823.

Bohus, B., Cs. Nyakas, and K. Lissak. 1968. Involvement of suprahypothalamic structures in hormonal feedback action of corticosteroids. Acta Physiol. (Hung.) 34:1-8.

Bouille, C. and J.D. Bayle. 1975. Adrenal cortical activation induced by hypothalamic stimulation and stress in pigeons bearing ectopic pituitary autographs. Neuroendocrinology 18:35-41.

Bouille, C., S. Herbute, and J.D. Bayle. 1975. Effects of hypothalamic deafferentation on basal and stress-induced adrenocortical activity in the pigeon. J. Endocrinol. 66:413-419.

Bouille, C. and J.D. Bayle. 1976. Comparison between hypothalamic, hippocampal, and septal area multiple unit activity and basal corticotrophic function in unrestrained, unanesthetized resting pigeons. Neuroendocrinology 22:164-174.

Brodish, A. 1963. Diffuse hypothalamic system for the regulation of ACTH secretion. Endocrinology 73:727-735.

Bush, E. 1953. Species differences and other factors influencing 
adrenocortical secretion. Ciba Found. Colloq. Endocrinol. 7:210232.

Cann, M.C., Z.Z. Zawidzka, J.M. Airth, and H.C. Grice. 1965. The effect of ether anesthesia on plasma corticosteroids and hematologic responses. Can. J. Physiol. Pharmacol. 43:463-468.

Cheifetz, P., N. Gaffud, and J.F. Dingman. 1968. Effects of bilateral adrenalectomy and continuous light on the circadian rhythm of corticotropin in female rats. Endocrinology 82:1117-1124.

Critchlow, V., R.A. Libelt, M. Bar-Sela, W. Mountcastle, and H.S. Lipscomb. 1963. Sex difference in resting pituitary-adrenal function in the rat. Am. J. Physiol. 205:807-815.

Dallman, M.F., W.C. Engeland, J.C. Rose, C.W. Wilkinson, J. Shinsako, and F. Siedenburg. 1978. Nychthemeral rhythm in adrenal responsiveness to ACTH. Am. J. Physiol. 235:R210-R218.

Daughaday, W.H. 1957. Corticosteroid binding by plasma alpha globulin. J. Clin. Invest. $36: 881-882$.

David-Nelson, M.A. and A. Brodish. 1969. Evidence for a diurnal rhythm of corticotrophin-releasing factor (CRF) in the hypothalamus. Endocrinology 85:861-866.

Dixit, B.N. and J.P. Buckley. 1967. Circadian changes in brain 5-hydroxytryptamine and plasma corticosterone in the rat. Life Sci. 6:755-758.

Dunn, J., R. Dyer, and M. Bennett. 1972. Diurnal variation in plasma corticosterone following long-term exposure to continuous illumination. Endocrinology 90:1660-1663.

Endroczi, E. and K. Lissak. 1963. Effect of hypothalamic and brain stem structure stimulation on pituitary-adrenocortical function. 
Acta Physiol. (Hung.) 24:67-77.

Endroczi, E., G. Schreiberg, and K. Lissak. 1963. The role of central nervous activating and inhibitory structures in the control of pituitary-adrenocortical function. Effects of intracerebral cholinergic and adrenergic stimulation. Acta Physior. (Hung.) $24: 211-221$.

Engeland, W.C. and M.F. Dallman. 1975. Compensatory adrenal growth is neurally mediated. Neuroendocrinology 19:352-362.

Ferrari, E., P.A. Bossolo, A. Vailati, I. Martinelli, A. Rea, I. Nosari. 1977. Variations circadiennes des effets d'une substance vagolytique sur le systeme ACTH-secretant chez l'homme. Annales d'Endocrinologie 38:203-213.

Folkow, B., B. Johansson, and B. Oberg. 1959. A hypothalamic structure with a marked inhibitory effect on tonic sympathetic activity. Acta Physiol. Scand. 47:262-270.

Gala, R.R. and U. Westphal. 1965. Corcosteroid-binding globulin in the rat. Studies on the sex difference. Endocrinology 77:841-851. Galicich, J.H., F. Halberg, L.A. French, and F. Ungar. 1965. Effect of cerebral-ablation on a circadian pituitary adrenocorticotropic rhythm in C. mice. Endocrinology 76:895-901.

Gibbs, F.P. 1976. Correlation of plasma corticosterone levels with running activity in the blinded rat. Am. J. Physiol. 231:817-821. Grollman, A. 1957. The pathenogenesis of adrenal regeneration. The Endocrine Society, 39th meeting, N.Y.

Guillemin, R., W.E. Dear, and R.A. Liebelt. 1959. Nychthemeral variations in plasma free corticosteroid levels of the rat. Proc. Soc. Exp. Biol. Med. 101:394-395. 
Guyton, A.C. 1976. Textbook of Medical Physiology. W.B. Sanders Co., Philadelphia. 1194 pp.

Halasz, B. and J. Szentagothai. 1959. Histologischer Beweis einer nervosen Signalubermittlung von der Nebennierenrinde zum Hypothalamus. Z. Zellforsch 50:297-306.

Halasz, B., M.A. Slusher, and R.A. Gorski. 1967. Adrenocorticotrophin hormone secretion in rats after partial or total deafferentation of the medial basal hypothalamus. Neuroendocrinology 2:43-55. Halberg, R., R.E. Peterson, and R.H. Silber. 1959. Phase relations of 24-hour periodicities in blood corticosterone, mitoses in cortical adrenal parenchyma, and total body activity. Endocrinology 64:222230.

Haus, E. 1964. Periodicity in response and susceptibility to environmental stimuli. Ann. N.Y. Acad. Sci. 118:292-319.

Hedge, G.A. and P.G. Smelik. 1968. Corticotropin release: inhibition by intrahypothalamus implantation of atropine. Science 159:891-892. Hiroshige, T. and M. Sakakura. 1971. Circadian rhythm of corticotropinreleasing activity in the hypothalamus of normal and adrenalectomized rats. Neuroendocrinology 7:25-36.

Hiroshige, T., K. Abe, S. Wada, and M. Kaneko. 1973. Sex differences in circadian periodicity of CRF activity in the rat hypothalamus. Neuroendocrinology $11: 306-320$.

Hiroshige, T. and S. Wada-Okada. 1973. Diurnal changes of hypothalamic content of corticotropin-releasing activity in female rats at various stages of the estrus cycle. Neuroendocrinology 12:316-319. Hodges, J.R. and S. Mitchley. 1970. Effect of training on the release of corticotropin in response to minor stressful procedures in the 
rat. J. Endocrinol. 47:253-254.

Hoimquest, D.L., K. Retienne, and H.S. Lipscomb. 1966. Circadian

rhythms in rats: effects of random lighting. Science 152:662-664. Horton, R., T. Kato, and R. Sherins. 1967. A rapid method for estimation of testosterone in male plasma. Steroids 10:245-256. Johnson, J.H., J. Terkel, D.I. Whitmoyer, and C.H. Sawyer. 1971. A circadian rhythm in the multi-unit activity (MUA) of preoptic neurons in the female rat. Anat. Rec. 169:348.

Johnson, J.T. and S. Levine. 1973. Influence of water deprivation on adrenocortical rhythms. Neruoendocrinology 11:268-273.

Kawai, A. and F.E. Yates. 1966. Interference with feedback inhibition of adrenocorticotrophin release by protein-binding of corticosterone. Endocrinology 79:1040-1046.

Kawai, A. and N. Kuzuya. 1972. Studies on the role of the pituitary gland in biosynthesis of corticosteroid-binding globulin in the rat. Endocrinol. Japan. 19:19-26.

Kawamura, H. and N. Ibuka. 1978. The search for circadian rhythm pacemakers in the light of lesion experiments. Chronobiologia 5:69-88. Keller, N., U.I. Richardson, and F.E. Yates. 1969. Protein binding and the biological activity of corticosteroids: in vivo induction of hepatic and pancratic alanine aminotransferases by corticosteroids in normal and estrogen-treated rats. Endocrinology 84:49-62.

Kinson, G.A. and C. Liu. 1973. Diurnal variations in plasma testesterone of the male laboratory rat. Hormon. Metab. Res. 5:233-234.

Kiss, T. 1951. Experimentel-morphologische Analyse der Nebenniereninnervation. Acta Anat. 13:81-89.

Koizumi, K. and H. Nishino. 1976. Circadian and other rhythmic 
activity of neurons in the ventromedial nuclei and lateral hypothatamic area. J. Physiol. (Lond.) 263:331-356.

Kovach, A.G.B., E. Monos, E. Koltay, and A. Desrius. 1970. Effect of hypothalamic stimulation on adrenal blood flow and glycocorticoid release prior to and after acute hypophysectomy. Acta Physiol. (Hung.) 38:205-216.

Krieger, D.T., A.I. Silverberg, F. Rizzo, and H.P. Krieger. 1968. Abolition of circadian periodicity of plasma 17-0HCS levels in the cat. Am. J. Physiol. 215:959-968.

Krieger, D.T. and F. Rizzo. 1969. Serotonin mediation of circadian periodicity of plasma 17-hydroxycorticosteroids. Am. J. Physiol. 217:1703-1707.

Krieger, H.P. and D.T. Krieger. 1970. Chemical stimulation of the brain: effect on adrenal corticoid release. Am. J. Physiol. 218: $1632-1641$.

Krieger, D.T. 1972. Circadian corticosteroid periodicity: critical period for abolition by neonatal injection of corticosteroid. Science 178:1205-1207.

Krieger, D.T. 1973. Effect of ocular enucleation and altered 1ighting regimens at various ages on the circadian periodicity of plasma corticosteroid levels in the rat. Endocrinology 93:1077-1091. Krieger, D.T. 1974. Food and water restriction shifts corticosterone, temperature, activity, and brain amine periodicity. Endocrinology 95:1195-1201.

Krieger, D.T. 1977. Regulation of the circadian periodicity of plasma ACTH levels. Ann. N.Y. Acad. Sci. 297:561-567.

Krieger, D.T., H. Hauser, and L.C. Krey. 1977. Suprachiasmatic nuclear 
lesions do not abolish food-shifted circadian adrenal and temperature rhythmicity. Science 197:398-399.

Krieger, D.T. and H. Hauser. 1978. Comparison of synchronization of circadian corticosteroid rhythms by photoperiod and food. Proc. Nat1. Acad. Sci. U.S.A. 75:1577-1581.

L'Age, M., A. Gonzales-Luque, and F.E. Yates. 1970. Adrenal blood flow dependence of cortisol secretion rate in unanesthetized dogs. Am. J. Physiol. 219:281-287.

Latner, A.L., D.B. Cook, and K.U. Solanki. 1977. Inhibition of binding of corticotrophin-(1-24)-tetracosapeptide (synacthen) to membrane receptors of adrenal cortex by cortisol. Biochem. J. 164:477-480.

Leme, J.G. and D.L. Wilhelm. 1975. The effects of adrenalectomy and corticosterone on vascular permeability responses in the skin of the rat. Br. J. Exp. Patho1. 56:402-407.

Levin, R. and S. Levine. 1975. Development of circadian periodicity in base and stress levels of corticosterone. Am. J. Physiol. 229: 1397-1399.

Manning, J.W., Jr. and C.N. Peiss. 1960. Cardiovascular responses to electrical stimulation in the diencephalon. Am. J. Physiol. 198: $366-370$.

Makoff, R., S. Roberts, and D.D. Fowler. 1964. Stimulation of corticosteroidogenesis in adrenal homogenates by serum proteins. J. Biol. Chem. 239:4124-4131.

Martel, P.J., P.W. Sharp, S.A. Slovach, and H.P. Vipond. 1962. Roles of adrenocortical steroids and glomerular filtration rate in the mechanism of the diurnal rhythm of water and electrolyte excretion. J. Endocrinol. 24:159-169. 
Mason, G.M.C., S.B. Koritz, and F.G. Peron. 1958. Corticosteroid formation in regenerating rat adrenals. Endocrinology 62:229-233. Matsui, N. and J.E. Plager. 1966. In vitro physiological activity of protein-bound and unbound cortisol. Endocrinology 78:1159-1164. McCarthy, J., R.C. Corley, and M.X. Zarrow. 1960. Diurnal rhythms in plasma corticosterone and lack of diurnal rhythm in plasma compound F-like material in the rat. Proc. Soc. Exp. Biol. Med. 104: 787-789.

Meier, A.H. 1975. Chronoendocrinology of vertebrates. In: B.E. Eleftheriou and R.L. Sprott (eds.), "Hormonal Correlates of Behavior." Plenum Press, N.Y. pp. 469-549.

Meier, A.H. and A.K. Srivastava. 1975. Alteration by drugs of the daily rhythm of plasma corticosteroid concentration in the gulf killifish, Fundulus grandis. Gen. Comp. Endocrinol. 26:253-258. Meier, A.4. 1976. Daily variation in concentration of plasma corticosteroid in hypophysectomized rats. Endocrinology 98:1475-1479. Meier, A.H., A.J. Fivizzani, and J.E. Ottenweller. 1978. Daily rhythm of plasma corticosterone binding activity in the whitethroated sparrow, Zonotrichia albicollis. Life Sci. 22:401-406. Mitsuma, T., J. Colucci, L. Shenkman, and C.S. Hollander. 1972. Rapid simultaneous radio-immunoassay for trijodothyronine and thyroxine in unextracted serum. Biochem. Biophys. Res. Commun. $46: 2107-2113$.

Miyabo, S. and T. Hisada. 1975. Sex difference in ontogenesis of circadian adrenocortical rhythm in cortisone-primed rats. Nature 256:590-592.

Moore, R.Y. and H.B. Quavi. 1971. Circadian rhythm in adrenal adenyl 
cyclase and corticosterone abolished by median forebrain bundle transection in the rat. Experientia 27:249-250.

Moore, R.Y. and V.B. Eichler. 1972. Loss of a circadian adrenal corticosterone rhythm following suprachiasmatic lesions in the rat. Brain Res. 42:201-206.

Morimoto, Y., K. Arisue, and Y. Yamamura. 1977. Relationship between circadian rhythm of food intake and that of plasma corticosterone and effect of food restriction on circadian adrenocortical rhythm in the rat. Neuroendocrinology 23:212-222.

Mountcastle, V.B. 1967. "Medical Physiology," ed. 13. C.V. Mosby Co., St. Louis. 1807 pp.

Murphy, B.E.P. 1969. Some studies of the protein-binding steroid and their application to the routine micro and ultramicro measurement of various steroids in body fluids by competitive protein-binding radioassay. J. Clin. Endocrinot. 27:973-990.

Naumenko, E.V. 1973. "Central regulation of the pituitary-adrenal complex." Consultants Bureau, N.Y.

Ney, R.L., N.S. Shimuzu, W.E. Nicholson, D. Island, and G.W. Liddle. 1963. Correlation of plasma ACTH concentration with adrenocortical response in normal human subjects, surgical patients, and patients with Cushing's disease. J. Clin. Invest. 42:1669-1677. Nichols, C.T. and F.H. Tyler. 1967. Diurnal variation in adrenal cortical function. Ann. Rev. Med. 18:313-324.

Nishino, H., K. Koizumi, and C. MacBrooks. 1976. The role of the suprachiasmatic nuclei of the hypothalamus in the production of circadian rhythm. Brain Res. 112:45-59.

Orth, D.N., D.P. Island, and G.W. Liddle. 1967. Experimental of the 
circadian rhythm in plasma cortisol (17-OHCS) concentration in man. J. Clin. Endocrinol. 27:549-555.

Ottenweller, J.E. and A.H. Meier. 1978. Neonatal cortisol treatment delays onset of daily variation of plasma corticosteroids in male rats. IRCS Med. Sci. 6:128.

Ottenweller, J.E., A.H. Meier, B.R. Ferrell, N.D. Horseman and A. Proctor. 1978. Extrapituitary regulation of the circadian rhythm of plasma corticosteroid concentration in rats. Endocrinology 103: 1875-1879.

Ottenweller, J.E., A.H. Meier, A.C. Russo, and M.E. Frenzke. 1979. Circadian rhythms of plasma corticosterone binding activity in the rat and the mouse. Acta Endocrinol. (in press).

Palka, Y., D. Coyer, and V. Critchlow. 1969. Effects of isolation of medial basal hypothalamus on pituitary-adrenal and pituitaryovarian function. Neuroendocrinology 5:333-349.

Pegg, P.J. and P.M. Keane. 1969. The simultaneous estimation of plasma cortisol and transcortin binding characteristics by a competitive protein binding technique. Steroids 14:705-715.

Phelps, C.R., I. Lengvari, A.J. Carrillo, and C.H. Sawyer. 1978.

Changes in diurnal fluctuations of plasma thyroid stimulating hormone and corticosterone following anterior hypothalamic deafferentation in the rat. Brain Res. 141:283-292.

Pincus, G. 1943. A diurnal rhythm in the excretion of urinary ketosteroids by young men. J. Clin. Endocrinol. 3:195-199.

Ramaley, J.A. 1972. Changes in daily serum corticosterone values in maturing male and female rats. Steroids 20:185-197.

Reis, D.J., M. Winbren, and A. Corvelli. 1968. A circadian rhythm 
of norepinephrine regionally in cat brain: its relationship to environmental lighting and to regional diurnal variation in brain serotonin. J. Pharmacol. Exp. Ther. 164:135-145.

Reis, D.J., A. Corvelli, and J. Conners. 1969. Circadian and ultradian rhythms of serotonin regionally in cat brain. J. Pharmacol. Exp. Ther. 167:328-333.

Richardson, U.I. and F.E. Yates. 1964. Protein binding and biological activity of corticosteroids: response of rat heart to cortocosterone $(B)$ in the presence of serum corticosteroid-binding proteins. Fed. Proc. 23:357.

Rotsztejn, W.H., A. Beaudet, A.G. Roberge, J. Lalonde, and C. Fortier. 1977. Role of brain serotonin in the circadian rhythm of corticosterone secretion and the corticotropic response to adrenalectomy in the rat. Neuroendocrinology 23:157-170.

Saba, G.C., A. Carnicelli, P. Saba, and V. Marescotti. 1963. Diurnal rhythm in the adrenal cortical secretion and in the rate of metabolism of corticosterone in the rat. Acta Endocrinol. 44:413-415.

Sadow, J., S. Knight, and W.J. Irvine. 1974. Dirunal variation in the response to ACTH. Proc. Roy. Soc. Med. 67:34-35.

Sandberg, A.A. and W.R. Slaunwhite Jr. 1959. Transcortin: a corticosteroid-binding protein of plasma. II. Levels in various conditions and the effects of estrogens. J. Clin. Invest. 38:1290-1297.

Sandberg, A.A., W.R. Slaunwhite Jr. and A.C. Carter. 1960. Transcortin: a corticosteroid-binding protein of plasma. III. The effects of various steroids. J. Clin. Invest. 39:1914-1926.

Sato, T. and J.C. George. 1973. Diurnal rhythm of corticotropinreleasing factor activity in the pigeon hypothalamus. Can. J. 
Physiol. Pharmaco1. 51:743-747.

Sato, T., M. Sato, J. Shinsako, and M.F. Dallman. 1975. Corticosteroneinduced changes in hypothalamic corticotropin-releasing factor (CRF) content after stress. Endocrinology 97:265-274.

Scapagnini, U., G.P. Moberg, G.R. van Loon, J. DeGroot, and W.F. Ganong. 1971. Relation of brain 5-hydroxytryptamine content to the diurnal variation in plasma corticosterone in the rat. Neuroendocrinology $7: 90-96$.

Schmitt, M. 1973. Circadian rhythmicity in response of cells in the lateral hypothalamus. Am. J. Physiol. 225:1096-1101.

Seggie, J., B. Shaw, I. Uhlir, and G.M. Brown. 1974. Baseline 24-hour plasma corticosterone rhythm in normal, sham-operated, and septally 1esioned rats. Neuroendocrinology 15:51-61.

Siegel, H.S., B.W. Mitchell, N.R. Gould, J.W. Latimer, and R.L. Wilson. 1977. Circadian rhythms for corticosterone, corticosteroid binding capacity, plasma glucose, heart rate, respiratory rate, and body temperature in white rock males. 5th Erup. Poultry. Cong. (Malta). pp. 1050-1057.

Simon, M.L. and R. George. 1975. Diurnal variations in plasma corticosterone and growth hormone as correlated with regional variations in norepinephrine, dopamine, and serotonin content of rat brain. Neuroendocrinology 17:125-138.

Singh, R.K., J.P.N. Chansouria, and K.N. Udupa. 1975. Circadian periodicity of plasma cortisol (17-OHCS) levels in normal, traumatized, corticotropin, and dexamethasone treated rabbits. Indian J. Med. Res. 63:793-798.

Scheving, L.E. and J.E. Pauly. 1966. Effect of light on corticosterone 
levels in plasma of rats. Am. J. Physiol. 210:1112-1117.

Slaunwhite, W.R. Jr. and A.A. Sandberg. 1959. Transcortin: a

corticosteroid-binding protein of plasma. J. Clin. Invest. 38: 384-391.

Slaunwhite, W.R. Jr., G.N. Lockie, N. Back, and A.A. Sandberg. 1962. Inactivity in vivo of transcortin-bound cortisol. Science 135: 1062-1063.

Slusher, M.A. 1964. Effects of chronic hypothalamic lesions on diurnal and stress corticosteroid levels. Am. J. Physiol. 206:1161-1164. Slusher, M.A. and J.E. Hyde. 1966. Effect of diencephalic and midbrain stimulation on ACTH levels in unrestrained cats. Am. J. Physiol. 210:103-108.

Snedecor, G.W. and W.G. Cochran. 1967. "Statistical Methods," ed. 6. Iowa State University Press, Ames. pp. 481.

Srivastava, A.K. and A.H. Meier. 1972. Daily variation in concentration of cortisol in plasma in intact and hypophysectomized gulf killifish. Science 177:185-187.

Stephan, F.K. and I. Zucker. 1972. Circadian rhythms in drinking behavior and locomotor activity of rats are eliminated by hypothalamic lesions. Proc. Nat1. Acad. Sci. U.S.A. 69:1583-1586.

Suzuki, T., E.B. Romanoff, W.P. Koella, and C.K. Levy. 1960. Effect of diencephalic stimuli on 17-hydroxycorticosteroid secretion in unanesthetized dogs. Am. J. Physiol. 198:1312-1314.

Szentagothai, J., B. Flerko, B. Mes, and B. Halasz. 1965. "Hypothalamic regulation of the pituitary." Hungarian Academy of Sciences Press, Budapest, Hungary.

Takahashi, K., K. Inoue, K. Kobayashi, C. Hayafuji, Y. Nakamura, and 
Y. Takahashi. 1977. Effects of food restriction on circadian adrenocortical rhythm in rats under constant lighting conditions. Neuroendocrinology 23:193-199.

Takebe, K., M. Sakakura, and K. Mashimo. 1972. Continuance of diurnal rhythmicity of CRF activity in hypophysectomized rats. Endocrinology 90:1515-1520.

U7rich, R.S. and A. Yuwiler. 1973. Failure of 6-hydroxydopamine to abolish the circadian rhythm of serum corticosterone. Endocrinology $92: 611-617$.

Ungar, F. and F. Halberg. 1962. Circadian rhythm in the in vitro response of mouse adrenal to adrenocorticotropic hormone. Science 137:1058-1060.

Ungar, F. 1963. In vitro studies of adrenal-pituitary circadian rhythms in the mouse. Ann. N.Y. Acad. Sci. 117:374-385.

Unsicker, K. 1971. On the innervation of the rat and pig adrenal cortex. Z. Zellforsch. 116:151-156.

Unsicker, K., J.H. Chamley, and G. Burnstock. 1977. Studies on the interactions between nerve fibres from para- and orthosympathetic ganglia and adreno-cortical and -medullary cells in joint culture. Cell Tiss. Res. 178:533-549.

Urquhart, J. 1965. Adrenal blood flow and the adrenocortical response to corticotropin. Am. J. Physiol. 209:1162-1168.

Ventura, M.A., L.M. Gonzalo, and F.M. Goni. 1977. Corticosterone secretion after neurogenic stress in intact and hypophysectomized rats. Experientia 33:686-687.

Voigt, M. 1944. Observations on some conditions affecting the rate of hormone output by the suprarenal cortex. J. Physiol. (Lond.) 
103:317-332.

Westphal, U. 1971. "Steroid-protein interactions." Springer-Verlag,

N.Y. p. 435.

Wilson, M. and V. Critchlow. 1973. Effect of fornix transection or hippocampectomy on rhythmic pituitary adrenal function in the rat. Neuroendocrinology 13:29-40.

Wilson, M. and V. Critchlow. 1974. Effect of septal ablation on rhythmic pituitary-adrenal function in the rat. Neuroendocrinology $14: 333-344$.

Wilson, M., J.M. McMillan, U.S. Seal, and K. Ahmed. 1976. Circadian variation of serum testosterone in the adult male rat with a late morning acrophase. Experientia 32:944-945.

Yasuda, N., K. Takebe, and M.A. Greer. 1976. Evidence of Nychthemeral periodicity in stress-induced pituitary-adrenal activation. Neuroendocrinology 21:214-224.

Zimmerman, E. and V. Critchlow. 1967. Effects of diurnal variation in plasma corticosterone levels on adrenocortical response to stress. Proc. Soc. Exp. Biol. Med. 125:658-663. 


\section{VITA}

John Edward Ottenweller was born on July 22, 1950 in Lake Charles, Louisiana. In the fall of 1968, after graduation from Immaculate High School in June of that year, he entered McNeese State University and in the fall of 1969 he transferred to Louisiana State University. He graduated from Louisiana State University in the fall of 1971 with a Bachelor of Science degree in Zoology. In 1972, he entered the graduate school at Louisiana State University and was granted a Master of Science degree in Z00logy in May 1975. In August of that year he entered the doctoral degree program in the Department of Zoology and Physiology at Louisiana State University where he is presently a candidate for the degree of Doctor of Philosophy with a major in Physiology and minors in Biochemistry and Nuclear Science. 
Candidate: John Edward Ottenweller

Major Field: $\quad$ Physlology

Title of Thesis: Extrapituitary Regulation of the Circadian Rhythm of Plasma Corticosteroid Concentration in Rats

Approved:

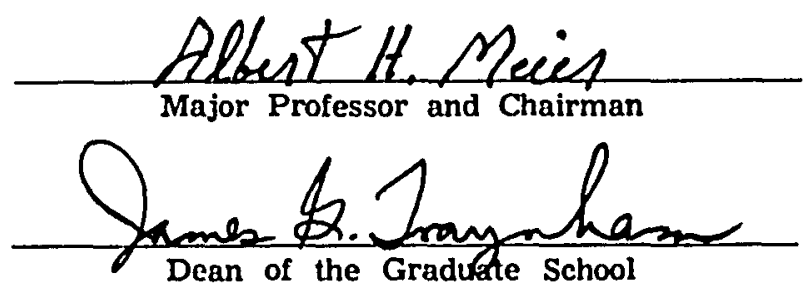

EXAMINING COMMITTEE:

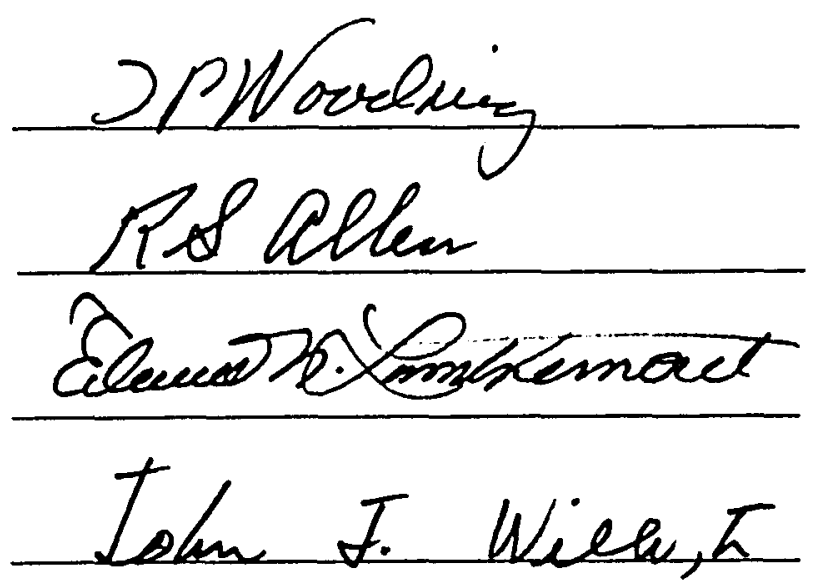

Date of Examination:

March 8, 1979 